\title{
Clinical and genetic heterogeneity of primary ciliopathies (Review)
}

\author{
INA OFELIA FOCȘA ${ }^{1}$, MAGDALENA BUDIȘTEANU ${ }^{2-4}$ and MIHAELA BĂLGRĂDEAN ${ }^{5,6}$ \\ ${ }^{1}$ Department of Medical Genetics, University of Medicine and Pharmacy 'Carol Davila', 021901 Bucharest; \\ ${ }^{2}$ Department of Pediatric Neurology, 'Prof. Dr. Alexandru Obregia' Clinical Hospital of Psychiatry, 041914 Bucharest; \\ ${ }^{3}$ Medical Genetic Laboratory, 'Victor Babeș’ National Institute of Pathology, 050096 Bucharest; \\ ${ }^{4}$ Department of Medical Genetics, Titu Maiorescu University, 040441 Bucharest; \\ ${ }^{5}$ Department of Pediatrics and Pediatric Nephrology, Emergency Clinical Hospital for Children 'Maria Skłodowska Curie'; \\ ${ }^{6}$ Department of Pediatrics, University of Medicine and Pharmacy 'Carol Davila', 077120 Bucharest, Romania
}

Received April 11, 2021; Accepted June 28, 2021

DOI: $10.3892 / \mathrm{ijmm} .2021 .5009$

\begin{abstract}
Ciliopathies comprise a group of complex disorders, with involvement of the majority of organs and systems. In total, $>180$ causal genes have been identified and, in addition to Mendelian inheritance, oligogenicity, genetic modifications, epistatic interactions and retrotransposon insertions have all been described when defining the ciliopathic phenotype. It is remarkable how the structural and functional impairment of a single, minuscule organelle may lead to the pathogenesis of highly pleiotropic diseases. Thus, combined efforts have been made to identify the genetic substratum and to determine the pathophysiological mechanism underlying the clinical presentation, in order to diagnose and classify ciliopathies. Yet, predicting the phenotype, given the intricacy of the genetic cause and overlapping clinical characteristics, represents a major challenge. In the future, advances in proteomics, cell biology and model organisms may provide new insights that could remodel the field of ciliopathies.
\end{abstract}

\section{Contents}

1. Introduction

2. Cilium

3. Ciliopathies

4. Conclusions

\section{Introduction}

Ciliopathies comprise a heterogeneous group of genetic disorders caused by structural or functional disruption of cilia, or

Correspondence to: Dr Ina Ofelia Focșa, Department of Medical Genetics, University of Medicine and Pharmacy 'Carol Davila', 3-5 Pierre de Coubertin Boulevard, 021901 Bucharest, Romania E-mail: ina.focsa@umfed.ro

Key words: cilia, ciliopathies, signaling, oligogenic, modifier, epistasis, pleiotropy by abnormal cilia biogenesis $(1,2)$. The two main subcategories, namely motile and immotile/primary ciliopathies, both involve disruption of the cilium, and also share several causal genes (3-5). However, clinically, they are quite different; while motile ciliopathies (Kartagener syndrome and primary ciliary dyskinesia) are characterized by pulmonary disease, infertility, situs inversus or reversal of organ laterality (6), primary ciliopathies include a wide class of diseases that range from organ-specific disorders to pleiotropic syndromes with multiorgan involvement. These distinct phenotypes may be explained through the structural differences between primary and motile cilia, as well as their distinct functions (7).

The aim of the present review was to comprehensively describe the primary ciliopathies, focusing on genetic heterogeneity, diagnosis and clinical aspects, with a brief overview of their biological basis.

\section{Cilium}

Structure. Motile cilia have been observed in protozoa since the early microscopy era (8). Unlike motile cilia, which are concentrated in clusters and line the respiratory tract, fallopian tubes, the efferent ductules of the testis and brain ventricles (9), the primary cilium is a single hair-like organelle, with variable length $(1-9 \mu \mathrm{m})(10)$, projecting from the apical surface of almost all types of cells, with certain exceptions (lymphocytes, granulocytes, hepatocytes and acinar cells) (11). Primary cilia are dynamic organelles that are assembled in the $G_{0} / G_{1}$ cell cycle stage and become disassembled with the onset of cell division (12).

Both types of cilia are structurally composed of a microtubule backbone, termed the axoneme, surrounded by matrix and covered by the ciliary membrane, which is continuous with the plasma membrane (Fig. 1). At the base of this ensemble, a specialized centriole, referred to as the basal body (BB), docks the cilium to the cell (13). The axoneme of the primary cilium consists of 9 outer doublet microtubules, $(9+0$ type), while motile cilia possess an extra inner pair of microtubules, reinforced by nexin bridges $(9+2$ type $)$ and an accessory structure involved in motility, formed of dynein arms and radial spokes (14). Each doublet contains a complete microtubule 
(A tubule) and one incomplete microtubule (B tubule), which are composed of tubulin protofilaments and are attached to each other through tektins and Ca-binding ribbon proteins (15). The BB structure contains 9 radially arranged microtubule triplets (A, B and C) and no central pair. The A and B tubules expand into the proximal segment of the cilium and are connected to the ciliary membrane by $\mathrm{Y}$ fibers, constituting a distinctive subcompartment known as the transition zone. Proximal to the $\mathrm{Y}$ fibers are the transitional fibers, which help to anchor the $\mathrm{BB}$ to the plasma membrane (16). The $\mathrm{BB}$ is responsible for the configuration of the microtubule scaffold and coordinates the ciliary trafficking pathway; thus, it is involved, together with transitional fibers, in ciliogenesis (17). Surrounding the transitional fibers are numerous strings of particles, acting as a selective filter for intraflagellar transport (IFT) molecules, known as the ciliary necklace $(18,19)$. In the distal region of the cilium, the backbone contains a single microtubule fiber (A tubule), which delimits the ciliary tip, a proteic zone with cell type-specific structure and function $(20,21)$. In addition to this classical structure of the cilia, there is evidence showing the existence of motile $9+0$ cilia, covering the node, which are responsible for left-right asymmetry, or sensory $9+2$ cilia, which are observed in the inner ear cells (22-26).

Function of the primary cilium. Since their discovery in the kidneys and the thyroid gland by Zimmermann in 1898, primary cilia have been considered as vestigial organelles, without a specific function, due to their lack of motility and their absence in several cells during mitosis (27). In 1975 , Webber and Lee (28) raised the hypothesis of a possible sensory role of mammalian nephron cilia, by comparing them to those in sensory tissues. This hypothesis was confirmed in 2000 in a study by Pazour et al (29), which presented experimental evidence showing the physiological function of the primary cilium. Once the implication of primary cilia in human diseases was demonstrated (30), the awareness of the significance of this organelle increased. Subsequently, a number of studies demonstrated the complex roles of primary cilia as mechanoreceptors, chemoreceptors and osmosensors (31-34).

A highly specialized process occurring in the ciliary compartment is the IFT: A bidirectional movement during which a protein complex (IFT particle) is shuttled along the microtubule backbone from the BB to the tip of the cilium (through kinesin-anterograde transport) and back (facilitated by dynein-retrograde transport) (35). As the synthesis of proteins essential for the development of cilia is not possible inside the ciliary compartment and proteins are carried through IFT, the importance of IFT in ciliogenesis must be emphasized, as well as its involvement in the delivery of signals from the cilium to the cell, higlighting its significant role in cilia-mediated signaling pathways (36).

Furthermore, $>25$ receptors and ion channels have been localized to the ciliary membrane, where a growing number of extracellular signals are received and transduced by the ciliary ensemble, facilitating certain signaling pathways that control the development of organs, as well as behavioral processes. Particularly important primary cilia-related signaling pathways include the following: Wingless (Wnt), Hedgehog (Hh), receptor tyrosine kinase (RTK), G-protein coupled receptors
(GPCRs), Notch, transforming growth factor- $\beta$ (TGF- $\beta$ ), mechanistic target of rapamycin (mTOR) and Salvador-Warts-Hippo (SWH) signaling. In addition, other signaling pathways that have been linked to primary cilia include extracellular matrix protein-mediated signaling, transient receptor potential channel-mediated signaling, vasopressin signaling in renal epithelial cells, somatostatin, serotonin and melanin-concentrating hormone signaling $(37,38)$.

The Wnt signaling pathway comprises a large family of secreted, cysteine-rich proteins, acting as a network of signal transduction pathways that are responsible for embryonic development, as well as tissue homeostasis and regeneration in adults (39). At least three signaling pathways have been described: The canonical Wnt pathway (or Wnt/ $\beta$-catenin pathway), and the non-canonical planar cell polarity (PCP) and $\mathrm{Wnt} / \mathrm{Ca}^{2+}$ pathways. The primary cilium and $\mathrm{BB}$ were found to be required for the regulation of both canonical and non-canonical Wnt signaling pathways. Canonical Wnt signaling acts through its end effectors as co-transcriptional factors, together with the T-cell factor/lymphoid enhancer factor 1 family of proteins, and co-activates the expression of Wnt target genes to modulate the cell cycle, leading to cell differentiation, proliferation, adhesion and migration, and tissue development (40). Canonical Wnt signaling appears to be directly or indirectly implicated in the formation of almost all organ systems during embryogenesis; it has been shown to be involved in anterior head fold formation and neuroectodermal patterning, in controlling further posterior patterning, as well as in the genesis and development of the heart, lungs, kidney, eyes, skin, blood cells and bone $(41,42)$. In addition, the essential role of the Wnt pathway in stem cell renewal has been highlighted $(42,43)$. The non-canonical PCP pathway appears to act independently on transcription and plays a key role in the modification and rearrangement of the actin cytoskeleton. Moreover, the molecular constituents of this pathway were shown to randomize the orientation of polarized epithelial cells and to coordinate the morphology and convergent extension of dorsal mesodermal and ectodermal cells during gastrulation and neural tube closure (44). Yet, the role of cilia in canonical Wnt signal transduction is controversial, although several studies have suggested the importance of primary cilia in the decrease of canonical Wnt signaling (45-47). By contrast, the contribution of the integrity of primary cilia to the non-canonical PCP Wnt pathway is well established. Movement of the BB to the apical cell surface and centriolar position are essential for the establishment of cell polarity; thus, defects in ciliary proteins implicated in ciliogenesis and BB migration lead to various PCP errors (48). The Wnt/ $\mathrm{Ca}^{2+}$ pathway shares a number of components with the PCP, but has been described as a separate pathway, which stimulates intracellular $\mathrm{Ca}^{2+}$ release from the endoplasmic reticulum. $\mathrm{Ca}^{2+}$ waves are hypothesized to serve as a key modulator in early pattern formation during embryo gastrulation. The $\mathrm{Wnt} / \mathrm{Ca}^{2+}$ pathway regulates embryogenesis in a complex manner, including promoting ventral cell fate, negative regulation of dorsal axis development, regulation of tissue separation and convergent extension movements during gastrulation, as well as heart formation. The Wnt/ $\mathrm{Ca}^{2+}$ pathway also functions as a critical modulator of both the canonical and PCP pathways (44). Wnt signaling 
A

$\mathrm{B}$ a

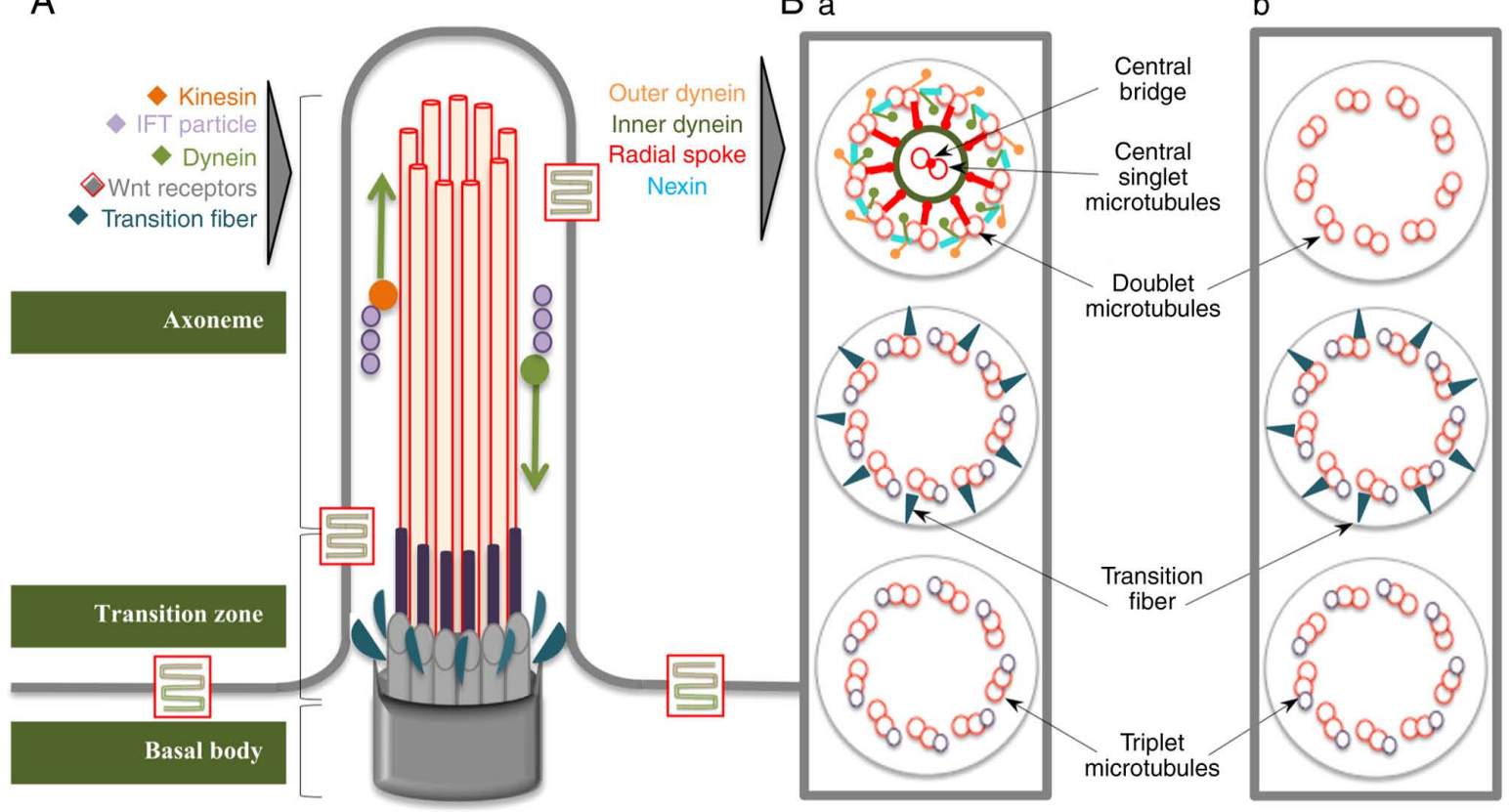

Figure 1. Schematic representation of the cilium structure. (A) Longitudinal section, (B-a) transversal view of the motile cilium and (B-b) transversal view of the primary cilium. IFT, intraflagellar transport; Wnt, wingless.

also regulates a number of other signaling pathways that have not been yet completely elucidated, but appear to be linked with myogenesis, axonal guidance, neuronal migration and synaptogenesis $(49,50)$.

Another key signaling pathway that was demonstrated to be essential for a variety of developmental processes is the $\mathrm{Hh}$ signaling pathway, described through its three Hh homologues: Desert Hh, Indian Hh (Ihh) and Sonic Hh (Shh). The Shh pathway, the most extensively investigated signaling pathway, functions due to the synergy of several molecule/proteins acting as transmembrane receptors, namely Patched homolog 1, Smoothened (SMO) and GLI transcription factors, leading to the transcription of Hh target genes (51). The role of Shh proteins emerges during embryonic development and morphogenesis, controlling left-right asymmetry, dorso-ventral axes and distal limb patterning. Moreover, proliferation of hematopoietic, retinal and neural stem cells, as well as development of epithelial tissues during organogenesis, appear to be modulated by Shh (52). Primary cilia are essential for the transduction of Hh signaling, playing a dual role through positive and negative regulation. It has been shown that abnormal cilia may lead to either loss-of-function $\mathrm{Hh}$ phenotypes in the neural tube, or gain-of-function Hh phenotypes in the limbs, indicating that the Hh pathway may play an important role in primary cilia biogenesis (38).

The migration, proliferation, differentiation and apoptosis of cells are also controlled by another cilia-related pathway, the platelet-derived growth factor receptor- $\alpha$ (PDGFR $\alpha$ ) pathway $(53,54)$. PDGFR $\alpha$ belongs to the large family of RTK transmembrane receptors and is required for activation of the Ras-Mek1/2-Erk1/2 pathway, thus causing axonemal reestablishment, cell cycle progression and chemotaxis (55). The development of numerous cells and tissues, including neurons, oligodendrocytes, astrocytes, alveolar smooth muscle cells, cardiac fibroblasts and bone cells, relies on PDGF $\alpha$ signaling (56). PDGFR $\alpha$, which is bound to the membrane of the primary cilium, regulates cytoskeletal reorganization to drive directional migration of fibroblasts in wound healing. Defects in primary cilia lead to abnormal wound healing. Moreover, disassembly of cilia, which allows the centriole to participate in mitosis during cell cycle progression, is modulated by PGFR $\alpha$ signaling (57). Along with this signaling, other RTK signaling pathways have recently been described, including EGFR, which plays an important role in mechanosensation and the migration of kidney epithelial cells or airway smooth muscle cells, and insulin-like growth factor receptor, which is involved in preadipocyte differentiation (37).

GPCRs comprise a large family of transmembrane receptors divided into six classes (A-F), for which $>30$ receptors belonging to the $\mathrm{A}$ (rhodopsin-like receptors), $\mathrm{B}$ (secretin receptor family) and $\mathrm{F}$ (frizzled/SMO-component of Shh signaling) classes are found on the ciliary membrane. Among these receptors, opsin, olfactory, serotonin (HTR6), somatostatin (SSTR3), vasopressin (V2R), dopamine (D1R,D2R and $\mathrm{D} 5 \mathrm{R}$ ) and prostaglandin (EP4) receptors are involved in a wide spectrum of cellular and physiological processes, including photoreception, olfactory sensation, feeding behavior, pain sensation, osmotic function in kidney cells, physiological function in cardiac myocytes, neuronal processes and energy homeostasis $(58,59)$. GPCRs are involved in neuronal or retinal cilia function and control the length of primary cilia or ciliogenesis. Conversely, absence or shortening of primary cilia may interfere with normal brain development, interneuron connectivity, gonadotropin hormone release at the nerve terminals or the sensory potential of cells (48).

In addition to these main signaling cascades, an increasing number of pathways have been associated with primary cilia. It has been concluded that the Notch signaling is involved in the physiology of primary cilia. Notch3 receptor, which is localized in the ciliary membrane, is activated by presenilin 2 , 
a ciliary $\mathrm{BB}$ enzyme, thereby regulating epidermal cell proliferation and differentiation (60). Loss of primary cilia or knockdown of IFT molecules may result in diminished Notch activation, leading to decreased cell proliferation and differentiation defects. In the neuroepithelia of the developing neural tube, activation of Notch signaling leads to increased primary cilium length, as well as accumulation of Smo molecules within the primary cilium. This interplay between the Notch and Shh pathways in primary cilia may specify ventral cell fate in the developing neural tube (38).

TGF- $\beta$ signaling has been recently associated with cilia, whereas TGF- $\beta 1$ and TGF- $\beta 2$ receptors are located on the ciliary tip. Primary cilia use diverse methods to regulate TGF- $\beta$ pathways, through SMAD2/3 and ERK1/2 activation by TGF stimulation, modulating various cellular processes, such as the differentiation of cardiomyocytes, osteocytes and myofibroblasts. Moreover, endothelial primary cilia, which act as flow sensors in the blood vessels, inhibit the endothelial-to-mesenchymal transition, and this process is related to attenuation of the TGF- $\beta$ signaling. There is also strong evidence regarding the impairment of mechanosensation and maturation in human osteoblasts due to shortening of primary ciliary length through TGF- $\beta$ signaling $(61,62)$.

The SWH pathway controls organ size and cell proliferation through a core of serine/threonine-kinases that interact with nephrocystin 4 or Crumbs 3 receptors located in the cilium. One of the major components of SWH signaling, MST1/2, which is localized to the $\mathrm{BB}$, has been found to be crucial for primary cilia biogenesis, with loss of MST1/2 leading to defects in ciliogenesis (63).

It has also been demonstrated that the primary cilium regulates mTOR signaling, which plays a pivotal role in metabolism and cell proliferation, thereby determining cell size, through the Lkb1 tumor suppressor, AMP-activated protein kinase and folliculin. In epithelial primary cilia, the mTOR pathway is upregulated by polycystin-1 through the tuberin protein, thus being involved in cyst formation $(64,65)$.

Brain-derived neurotrophic factor signaling, which is involved in neuronal development, synaptic plasticity, satiety and weight control, has recently been proposed to be linked with the BBS4 protein and primary cilia (66).

\section{Ciliopathies}

Given the notable complexity of interconnected signaling pathways in cilia, the role of the primary cilium as a cellular hub is becoming increasingly obvious; its clinical importance emerges from the consequences of its structural or functional defects, which lead to a broad category of disorders, collectively termed as ciliopathies.

The term 'ciliopathy' is most likely attributed to immotile or primary cilia-related disorders, and it has been recently allocated to certain conditions that have long been known as separate clinical entities (67). The first ciliophathy ever defined was Bardet-Biedl syndrome (BBS) in 2003 (68), although this disease had been known since 1866, when Laurence and Moon (69) first described the phenotype, including retinitis pigmentosa, mental retardation, hypogonadism and spastic paraplegia, in four cases. Decades later, a similar phenotype, consisting of obesity, retinal dystrophy,

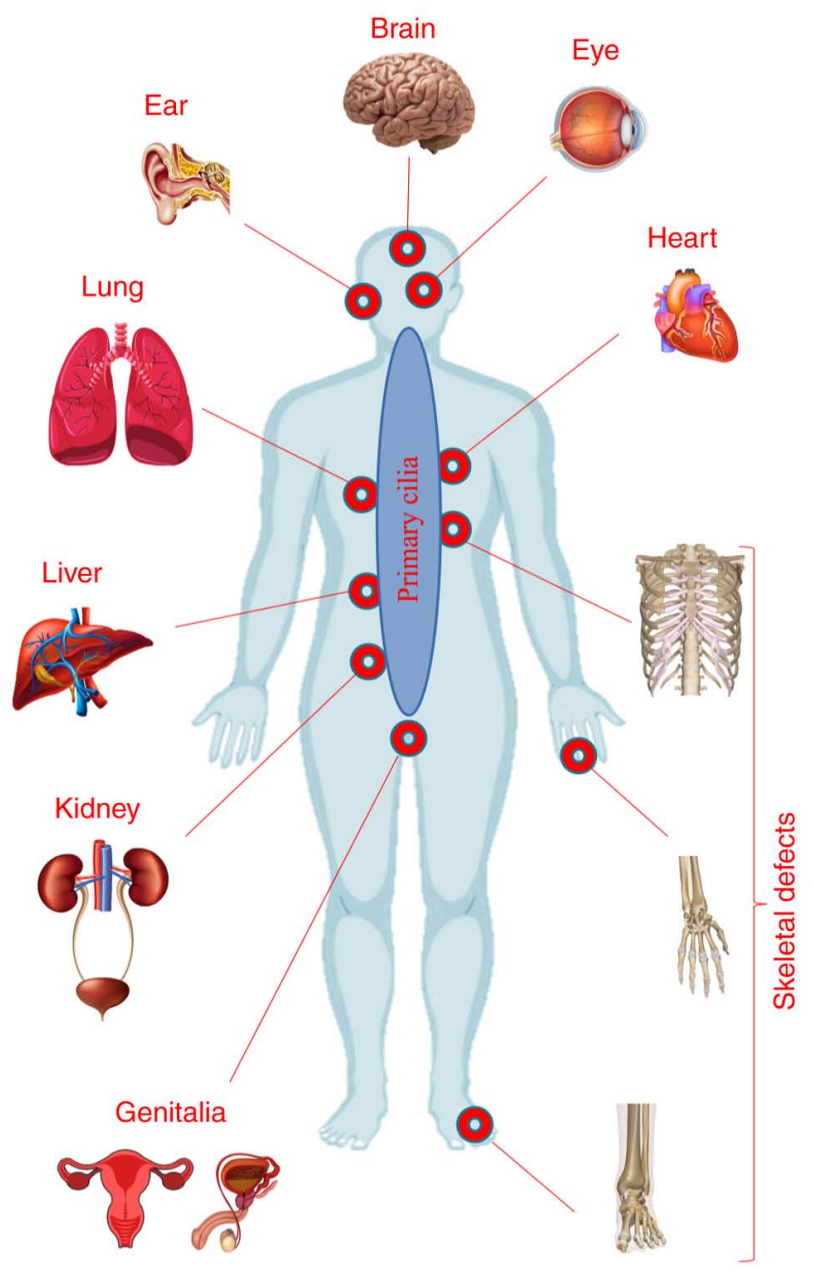

Figure 2. Organ and system involvement in primary ciliopathies.

polydactyly and cognitive problems with learning difficulties, was reported in 1920 by Bardet and in 1922 by Biedl (70).

Clinical overlaps in primary ciliopathies. As a result of the presence of primary cilia in nearly all tissues and organs, impairment of their structure or function may result in a vast group of phenotypes, ranging from single organ impairment to complex systemic disorders (Fig. 2). In addition to their isolated involvement, the kidney and the eyes (retina) are also implicated in defining the heterogeneous pattern of primary ciliopathies, with the participation of other organs, including the brain, skeletal system and liver (71). Additional system contributions in defining the ciliopathic clinical picture are summarized in Table I.

Renal manifestations. Renal impairment is the most common sign in primary ciliopathies, histologically characterized by renal cysts, a thickened and irregular tubular basement membrane, and interstitial fibrosis. Clinically, two frequently observed categories have been defined: Polycystic kidney disease (PKD) and nephronophthisis (NPHP). Both entities are characterized by a progressive decline in renal function, eventually leading to renal failure $(72,73)$. The onset of the diseases varies. Some signs could be detected prenatally due to the presence of oligohydramnios and enlarged kidneys, or shortly after birth due to the occurrence of severe 
Table I. Additional clinical features of ciliopathies ${ }^{\mathrm{a}}$.

\begin{tabular}{ll}
\hline Type of system & \multicolumn{1}{c}{ Clinical feature } \\
\hline Cardiovascular & $\begin{array}{l}\text { Atrial or/and ventricular septal defects, dilated cardiomyopathy, hypertrophic cardiomyopathy and } \\
\text { valvular defects } \\
\text { Breathing abnormalities, respiratory insufficiency, pulmonary hypoplasia, atelectatic lungs and intersti- } \\
\text { tial fibrosis }\end{array}$ \\
Respiratory & $\begin{array}{l}\text { Panhypopituitarism, growth hormone deficiency, hypothyroidism, diabetes mellitus and hypogonadism } \\
\text { Endocrine }\end{array}$ \\
Genital & Pancreatic dysgenesis, pancreatic fibrosis and cystic pancreas \\
Pancreatic & Sensorial hearing loss \\
Aural &
\end{tabular}

${ }^{\text {a}}$ Features displayed in this table were collected after an overview analysis of OMIM clinical synopsis (www.omim.org). OMIM, Online Mendelian Inheritance in Man.

hypertension or respiratory insufficiency (74,75). During childhood, the symptoms of renal disease are unspecific and may include polydipsia, polyuria, secondary enuresis and urinary concentration defects. Poor growth may occur due to chronic dehydration. As a result of renal insufficiency and its progression to end-stage renal failure, new complications may develop, including anemia, metabolic acidosis, anorexia and/or hypertension (76). Renal ultrasound examination shows large, normal-sized or small kidneys, with increased echogenicity, loss of corticomedullary differentiation and the presence of renal cysts $(76,77)$. Dysplastic, lobulated or horseshoe kidneys, kidney malrotation and renal agenesis are less frequently encountered in ciliopathic disorders (78).

Liver manifestations. Liver cysts, liver fibrosis and ductal plate malformation with abnormal bile ducts may be summarized as liver fibrocystic diseases, and they are often found, in addition to PKD, in primary ciliopathies (79). The liver disease can remain asymptomatic, or it can lead to complications, particularly portal hypertension and esophageal varices, cholangitis or cholestasis (80). End-stage hepatic disease requiring transplantation has also been reported in some patients $(81,82)$. The cardinal symptom is hepatomegaly, which can be associated with elevated serum levels of hepatic enzymes, or liver hyperechogenicity on abdominal ultrasound (83).

Ocular manifestations. Retinal dystrophy (with both rod and cone photoreceptor involvement) is commonly encountered in primary ciliopathic disorders. The clinical manifestations of visual impairment range from night blindness, color blindness and loss of peripheral vision, to progressive visual loss and complete blindness (84). Disruptions of ocular motility, such as oculomotor apraxia and nystagmus, are also frequently described $(85,86)$. Additional ocular defects include strabismus, amblyopia, astigmatism, congenital cataracts and coloboma (78).

Central nervous system (CNS) manifestations. The major neuroimaging finding, which characterizes a distinct group of diseases referred to as Joubert syndrome (JS) and related disorders, is the 'molar tooth sign' (MTS), comprising cerebellar vermis hypoplasia or aplasia, with enlargement of the fourth ventricle, thickened and horizontalized superior cerebellar peduncles and a deepened interpeduncular fossa $(87,88)$. Neurological abnormalities may also include Dandy-Walker malformation (DWM), ventriculomegaly, periventricular nodular heterotopia, hydrocephalus, encephalocele/meningocele, polymicrogyria, absence of the pituitary gland, corpus callosum defects and morphological brainstem abnormalities (83,89-91). A wide range of clinical signs may be observed, such as hypotonia, ataxia, developmental delay, intellectual disability (ID), impaired or absent speech, behavioral disturbances such as hyperactivity and aggressiveness, and self-mutilation $(92,93)$.

Skeletal manifestations. Clinical manifestations of the skeletal system may vary from mild phenotypes, such as polydactyly, to severe deformities, possibly leading to death. Polydactyly of the hands and/or feet, which is usually post-axial, but may also be pre-axial and, in some cases, central or mesoaxial, is present in most individuals with cilia-related disorders (94-96). In addition to polydactyly, the hands and feet may be affected to various degrees by oligodactyly, syndactyly, camptodactyly, brachydactyly, carpal and tarsal shortening, short long bones, rhizomelic micromelia, fibular aplasia or limb agenesis $(97,98)$. Truncal skeletal defects may include a constrictive thoracic cage, with shortened and horizontalized ribs, which may be life-threatening in some cases; abnormal or absent clavicles, small scapulae and scoliosis may also be observed (99). Cranioskeletal characteristics include craniosynostosis, macro- or microcephaly, head shape anomalies, frontal bossing, a prominent forehead, bitemporal narrowing, cleft palate, zygomatic arch hypoplasia, maxillary hypoplasia and micrognathia (100).

\section{Diagnosis of primary ciliopathies}

Clinical diagnosis. Given the numerous overlapping features and marked genetic heterogeneity, considerable efforts have been made to diagnose and classify ciliopathies, in order to optimize clinical management of the patients and improve the accuracy of genetic counseling.

For some of these diseases with severe phenotypes leading to a high mortality rate in utero or during the perinatal period, a prenatal diagnosis is possible in the presence of 
Clinical diagnosis algorithm of primary ciliopathies

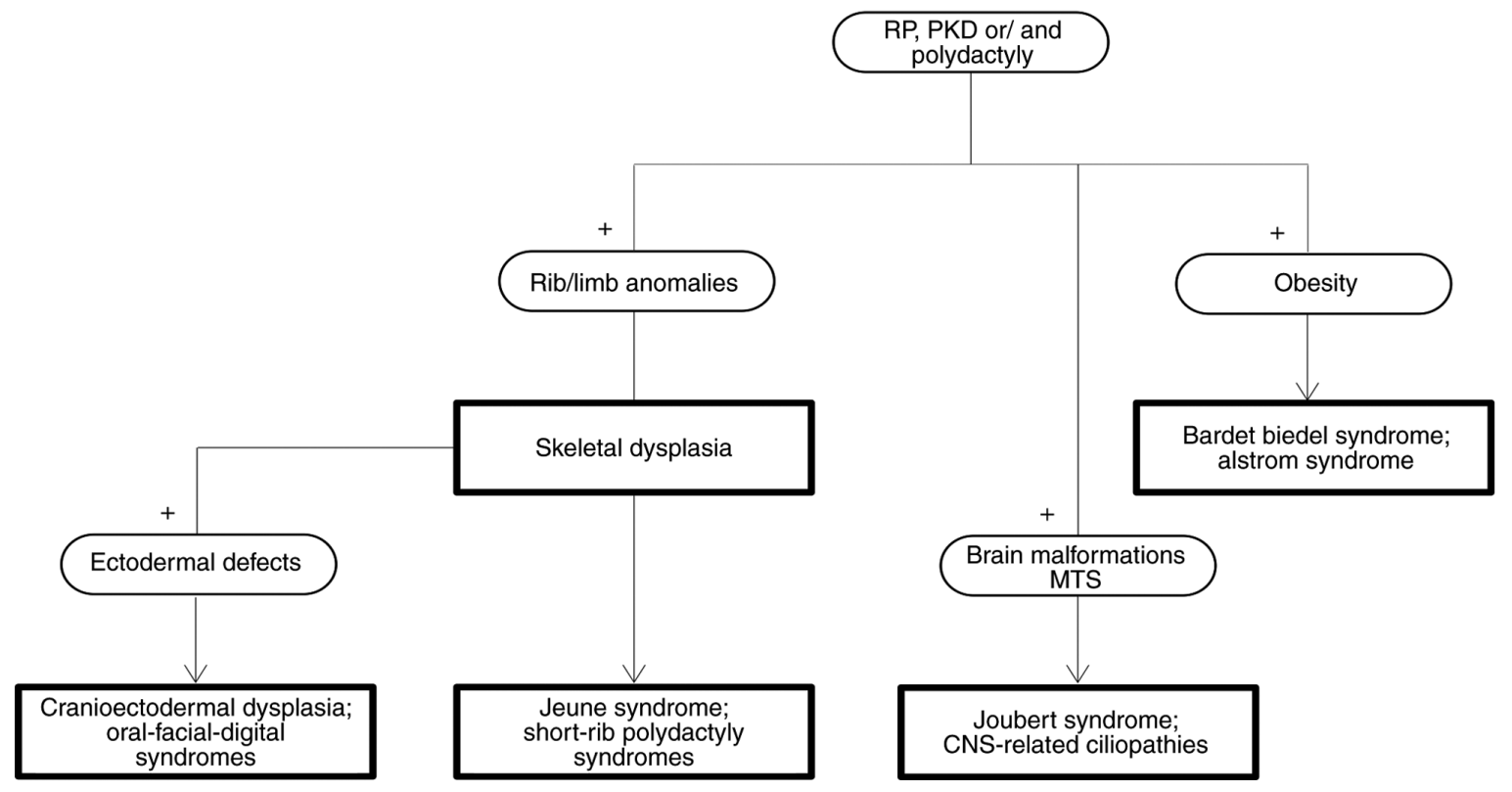

Figure 3. Diagram of the clinical diagnosis algorithm of primary ciliopathies. Adapted with permission from (107). MTS, molar tooth sign; PKD, polycystic kydney disease; RP, retinitis pigmentosa.

pathognomonic ultrasonographic signs in conjunction with $\alpha$-fetoprotein testing of the amniotic fluid and DNA testing of the fetus (101). Early in the pregnancy (weeks 8-11), ultrasonographic screening can detect certain fetal malformations, such as an enlarged cisterna magna or encephalocele (102). Between 11 and 14 weeks of pregnancy, enlarged polycystic kidneys or polydactyly may be detected (103), while later in the second trimester, other brain anomalies (e.g., DWM and hydrocephalus) (104) and severe skeletal anomalies (e.g., rhizomelic shortening of the long bones and hypoplastic thoracic cage) may be identified (105). Fetal MRI can detect MTS at 27 weeks of pregnancy (106).

Postnatally, Beales and Kenny proposed a clinical diagnosis algorithm starting with the presence of renal and retinal involvement and/or polydactyly (Fig. 3). Adding limb or rib abnormalities to this core of clinical manifestations may easily direct the diagnosis to ciliary skeletal dysplasias. Furthermore, identification of ectodermal defects in this group suggests the diagnosis of oral-facial-digital syndrome (OFDS) or cranioectodermal dysplasia (CED), while their absence indicates the diagnosis of short-rib polydactyly syndrome (SRPS). The detection of MTS and other CNS abnormalities should raise the suspicion of JS or JS-related disorders, whereas the presence of obesity points towards the diagnosis of BBS or Alström syndrome (ALMS) (107).

Genetics and molecular diagnosis. Since the description of the first ciliopathy gene, BBS6, by two distinct research groups in 2000 , due to the advances in genomic sequencing technologies, a number of genes have been associated with ciliary phenotypes $(108,109)$. Only in the last 5 years, through the intensive use of specific gene panels, whole exome and whole genome sequencing $>100$ new ciliary genes have been identified. At present, there are $>190$ known genes associated with recognized ciliopathies, of which $>140$ genes (Table SI) are implicated in primary ciliopathies. Other candidate genes $(>240)$, of which the protein products have been shown to be associated with cilia function or structure, may be involved in either new or confirmed primary or motile ciliopathies (110). Ciliopathies are considered to be Mendelian disorders (111), although a plethora of evidence has also indicated a non-Mendelian pattern of inheritance, or even environmental contribution to defining the phenotype. Genetic locus heterogeneity, copy number variants $(112,113)$, oligogenicity $(114,115)$, multiple allelism (116-119) and transposon-mediated mutagenesis (120) have been described, highlighting the marked complexity of the genetic mechanisms responsible for ciliopathic phenotypes. Moreover, the severity or variability of the phenotypes is suggested to be modulated by the pattern of ciliary gene expression and its effect on protein function (null, truncating or hypomorphic) (121), by epistatic interactions $(122,123)$ and by genetic modifiers or stochastic effects $(45,111,124-128)$.

Classification of primary ciliopathies. Several types of ciliopathies have been recognized, considering the level to which an organ is affected for defining their phenotype.

Retinal ciliopathies. Retinal ciliopathies include clinical entities manifesting as retinal degeneration, and they are caused by defective morphogenesis or dysfunction of specialized sensory cilia from the retina that form the outer segment of photoreceptors. Proteins, such as rhodopsin or ambient lighting-dependent proteins, are trafficked along these specialized primary cilia by means of IFT particles. Impairment of IFT leads to the accumulation of rhodopsin, defects in outer segment development and cell death, which result in the phenotype of retinal degeneration $(129,130)$. Among non-syndromic retinal ciliopathies, the ocular phenotype ranges from the most common 
retinitis pigmentosa [Mendelian Inheritance in Man (MIM), 26800] (47), which initially manifests as night blindness, followed by loss of peripheral vision, due to the impairment of rod photoreceptor function, and can progress to complete blindness $(84,131)$ to the most severe congenital retinal dystrophy, Leber congenital amaurosis (LCA; MIM, 204000), which frequently results in blindness within the first year of life. Visual loss is usually accompanied by sensory nystagmus, amaurotic pupillary response and absent electroretinogram signs. Photophobia, high refractive errors, keratoconus and enophthalmos are often seen in LCA. Involvement of the retina may range from normal, to retinal degeneration, retinal aplasia or biochemical dysfunction (dysplasia) (132). Overlapping with these two disorders, other ocular dystrophies have also been described as retinal ciliopathies: Cone dystrophy (MIM, 304020), characterized by visual loss and color vision defects, cone-rod dystrophy (MIM, 120970), characterized by photophobia, abnormal color vision, night and peripheral vision loss, and macular dystrophy (MIM, 300834), characterized by loss of color and sharp vision (133). Progressive retinal degeneration and sensorineural hearing loss are the first symptoms found in ALMS (MIM, 203800); these are accompanied later in childhood by obesity and diabetes mellitus. Additional features, such as cardiomyopathy, epilepsy, respiratory disturbance and renal or endocrine dysfunction, support the classification of these disorders as syndromic retinal ciliopathies (134). A rare combination of retinal and renal ciliopathies characterizes Senior-Løken syndrome (SLSN; MIM, 266900), with a specific clinical presentation consisting of retinal dystrophy and NPHP. Consequently, SLSN is considered by some studies as a syndromic retino-ciliopathy or, by others, as a renal (NPHP-related) ciliopathy $(135,136)$.

Renal ciliopathies. Renal ciliopathies encompass a group of disorders, the hallmark of which is kidney disease, including autosomal dominant polycystic kidney disease (ADPKD; MIM, 173900), autosomal recessive polycystic kidney disease (ARPKD; MIM, 263200) and NPHP (MIM, 256100). In the kidney, epithelial primary cilia lining the nephron tubules and collecting ducts act as sensory antennae sensitive to urine composition, osmolarity and flow. Defects in several signaling pathways, such as G-protein signaling, mTOR or Wnt, induced by decreased of flow-mediated intracellular calcium concentration, may lead to cyst formation. Moreover, disruption of the balance between canonical and non-canonical Wnt signaling may affect the polarity of epithelial tubular cells, also resulting in cyst formation (137).

ADPKD and ARPKD are different, not only due to the inheritance pattern, but also based on the microscopic and ultrasonographic appearance of the cysts, associated organ anomalies, age at onset, severity and prognosis (138). While ADPKD is characterized by large cysts originating from the distal nephrons and collecting ducts, which grow in volume and number with age, and by the presence of cysts in the liver, pancreas or other epithelial organs, intracranial aneurysms and mitral valve prolapse (139), the cysts in ARPKD are small, originate from the distal tubules and collecting ducts and display a salt-and-pepper pattern, and the liver is always affected by fibrosis (138). In contrast to ADPKD, which starts in late adulthood and slowly progresses to end-stage renal disease (ESRD),
ARPKD is more severe, with antenatal onset and diagnosis during late pregnancy or at birth, leading to increased perinatal death rate (30-50\%). Death occurs as a consequence of respiratory insufficiency due to pulmonary hypoplasia and thoracic compression by the extremely expanded kidneys (75). NPHP, which is characterized by corticomedullary cysts, atrophy and interstitial fibrosis resulting in nephron disintegration, is the main cause of ESRD in children (140). The severity and, subsequently, the progression to ESRD, depend on the clinical variant, namely the infantile, juvenile or adolescent variant. The infantile variant is the most severe, with prenatal manifestations consisting of oligohydramnios and bilateral enlarged cystic kidneys. Thus, ESRD develops in the first year of life. The first symptoms of the classical juvenile form, which is characterized by renal interstitial fibrosis and inflammation, with progression to tubular atrophy and small cyst formation, develop during the first decade of life and ESRD occurs at the mean age of 13 years (74). NPHP may be limited to the kidneys or may be part of other ciliopathic conditions, such as Joubert/COACH syndrome, SLSN, BBS, Meckel-Gruber syndrome (MKS) or skeletal disorders (141). BBS (MIM, 209900) is the most extensively investigated ciliopathy, and it has provided valuable data for the entire spectrum of human cilia-related disorders due to its overlapping characteristics at the level of phenotype, genotype, protein-protein interactions and participation in signaling pathways (142). BBS is a multisystem disorder, but renal impairment is its most prominent cause of morbidity and mortality. The major clinical characteristics, including retinal dystrophy, obesity, post-axial polydactyly, renal anomalies, cognitive impairment and hypogonadism, are suggestive of the diagnosis. The presence of four of those characteristics, or association of three primary characteristics with two secondary features is considered as sufficient for clinical diagnosis (143). Secondary features include speech delay, developmental delay, diabetes and congenital heart disease. BBS is characterized by marked clinical variability, which cannot be fully attributed to the 24 genes identified to date (144). MKS (MIM, 249000), which displays renal (cystic kidney dysplasia) as well as neurological [occipital encephalocele (OE)] manifestations, may be considered as either a renal or a CNS-related ciliopathy. Hepatic fibrosis completes the specific clinical triad of this condition, although polydactyly is often considered as the 4th pathognomonic feature (145). MKS has a heterogeneous, severe phenotype, which is not compatible with life, with death occurring in utero or shortly after birth. Renal dysfunction may often lead to oligohydramnios or anhydramnios. Apart from OE, which is the most frequent finding, additional CNS malformations found in MKS include olfactory bulb dysgenesis, optic nerve hypoplasia, agenesis of the corpus callosum, holoprosencephaly, cerebellar hypoplasia or total anencephaly. Cleft lip and palate, shortening of the long bones, congenital heart defects and pulmonary hypoplasia may further complicate the clinical picture $(45,101)$.

CNS-related ciliopathies. CNS-related ciliopathies comprise a group of conditions, the hallmark of which is the MTS, which is required for diagnosis. Impairment of the Wnt pathway, which is a major signaling pathway involved in cerebellar development, may be responsible for defective cerebellar vermis hypoplasia, one of the components of MTS. In addition 
to this pathway, other neuronal primary cilium-specific pathways are required for normal brain development, regulating neuronal fate, proliferation, migration and differentiation. Dysregulation of these pathways, including Shh, PDGFR $\alpha$ and GRCR, may manifest with malformations during cortical development or midline defects, which are often found in JS or CNS-related ciliopathies (71). Depending on the additional clinical characteristics, JS (MIM, 213300) has been classified into several groups as follows: i) Pure or classic JS, characterized by hypotonia, developmental delay, abnormal eye movements, breathing abnormalities, ataxia and ID; ii) JS with ocular defects, including retinal dystrophy or LCA; iii) JS with renal defects (NPHP); iv) JS with oculorenal defects, also named cerebello-oculorenal syndrome, comprising SLSN (retinal dystrophy, LCA and NPHP) associated with MTS, and Dekaban-Arima syndrome (cerebrooculohepatorenal syndrome) characterized by chorioretinal coloboma or retinal dystrophy, PKD, MTS and hepatic fibrosis in some cases; v) JS with congenital hepatic fibrosis; vi) JS with congenital hepatic fibrosis and associated chorioretinal coloboma, also known as COACH syndrome; and vii) JS with orofaciodigital defects, including a lobulated or bifid tongue, hamartomas, cleft lip and/or palate and polydactyly, also known as orofaciodigital syndrome type VI $(83,87)$. To date, $\sim 40$ causative genes covering $>90 \%$ of clinical subjects have been identified (146-152).

Ciliopathies with skeletal involvement. This group of disorders is characterized by variable severity, ranging from mild to severe or even lethal phenotypes. Two subgroups have been distinguished: Those with major skeletal system involvement, including craniofacial, thoracic cage and long bone involvement, known as short-rib thoracic dysplasias (SRTDs), with or without polydactyly or ciliary condrodysplasias, and OFDS, with milder involvement of the skeletal system (153).

Development of the cartilage and bones is a complex process that is modulated mainly by the IFT and Hh pathways. Disruption of Ihh signaling in chondral primary cilia affects chondrocyte maturation during the ossification process. Consequently, various skeletal abnormalities, including polydactyly, shortening of the ribs or long bones and craniofacial abnormalities, may occur $(154,155)$. Dysregulation of IFT, which is involved in the trafficking of the transmembrane SMO receptor, a signal transducer in Hh signaling, may lead to premature differentiation and decreased proliferation of chondrocytes, manifesting as specific SRTDs and defects of long bone growth plates (156).

There are $>19$ types of SRTDs, classified based on phenotype severity, radiological findings and confirmation of genetic defects $(100,157)$. Chondroectodermal dysplasia or Ellis-van-Creveld syndrome (EVC; MIM, 2255000), Weyers acrodental dysostosis (WAD; MIM, 193530) and Sensenbrenner syndrome or CED (MIM, 218330) are the milder disorders in this group. EVC is characterized by disproportionate short limb dwarfism, short ribs, polydactyly, cardiac malformations and ectodermal defects affecting the hair, teeth and nails (158-160). WAD is an allelic disorder to EVC, but displays a milder phenotype, consisting of moderate short stature, postaxial polydactyly, and nail and dental anomalies, and is inherited in an autosomal dominant manner (161). CED is characterized by craniofacial abnormalities, such as sagittal craniosynostosis, leading to dolichocephaly, frontal bossing and dental defects, in conjunction with skeletal abnormalities (short stature, rhizomelic limbs, brachydactyly and narrow thorax) and ectodermal anomalies (thin/sparse hair, hypoplastic nails and skin laxity) $(162,163)$. Kidney involvement (NPHP progressing to renal failure) and liver involvement (ranging from asymptomatic hepatomegaly to acute cholangitis, liver cirrhosis and severe cholestasis) are common findings in CED (164).

The second group with more severe phenotypes is comprised of Jeune asphyxiating thoracic dystrophy (JATD; MIM, 208500) and conorenal syndrome or Mainzer-Saldino syndrome (MZSDS; MIM, 266920). The specific presentation of JATD includes a constrictive thoracic cage and secondary respiratory distress due to restrictive pulmonary hypoplasia. Respiratory distress is the main cause of mortality in $\sim 60 \%$ of the patients (100). Additional skeletal findings may include a short stature, short limbs with irregular metaphyses, cone-shaped epiphyses in the hands, foot polydactyly, a shortened ilium and a trident-shaped acetabulum. Retinal degeneration, NPHP-like or cystic renal disease, pancreatic and liver involvement or brain malformations are occasionally found in patients with JATD $(100,165)$. MZSDS is characterized by the triad of retinal dystrophy, renal disease (typically NPHP) and phalangeal cone-shaped epiphyses (166). The thorax is less narrow compared with that in patients with JATD. Short stature, hepatic fibrosis and cerebellar ataxia are variable traits that may be observed in MZSDS $(166,167)$.

The last subtype is the perinatally lethal SRPS, the core features of which include a constrictive thoracic cage, significantly shortened long bones, polydactyly, brahydactyly and pelvic abnormalities (100). Different types have been characterized, based mainly on radiological findings: SRPS types I (Saldino-Noonan syndrome) and III (Verma-Naumoff syndrome) (MIM, 613091); SRP type II or Majewski syndrome (MIM, 263520); SRPS type IV or Beemer-Langer syndrome (MIM, 269860); and SRPS type V (MIM, 614091) (98). In addition to skeletal abnormalities, involvement of the brain, heart, kidneys, liver, pancreas and genitalia have often been recorded in SRPS. In some cases, facial dysmorphism may also be observed $(100,165)$.

Apart from the typical manifestations, some 'unusual' features may be observed in each group, further expanding and complicating the phenotype; these include atlantoaxial instability and spinal cord compression $(168,169)$, short irregularly bent ribs, hypoplastic and bent mesomelic bones, short campomelic long bones, undermineralized bones $(170,171)$, OE or MTS (172).

OFDS (MIM, 311200) describes a heterogeneous group of diseases caused by defects in $\sim 18$ genes (173-175). Clinical manifestations include anomalies of the face (micrognathia, hypertelorism, telecanthus, cleft lips and low-set ears), the oral cavity (gingival frenulae, lingual hamartomas, cleft/lobulated tongue and cleft palate) and the digits (polydactyly, brachydactyly, oligodactyly and bifid digits), associated with an extensive spectrum of additional features affecting the CNS, the kidneys, the heart or the eyes, outlining the 13 forms described to date $(173,176)$. In addition to renal involvement, which is commonly found in OFDS, a series of features overlapping with other ciliopathies (JS, SRPS and EVC) 
Table II. Newly defined ciliopathies.

\begin{tabular}{|c|c|c|c|c|}
\hline MIM ID & Disease name & Gene name & Protein localization & (Refs.) \\
\hline 616287 & $\begin{array}{l}\text { Lethal congenital contracturesyndrome; } \\
\text { hypomyelination neuropathy-arthrogryposis } \\
\text { syndrome }\end{array}$ & ADCY6 & Axoneme & $(184)$ \\
\hline 243605 & $\begin{array}{l}\text { Stromme syndrome; lethal fetal brain } \\
\text { malformation-duodenal atresia-bilateral } \\
\text { renal hypoplasia syndrome; microcephaly }\end{array}$ & CENPF & Basal body & $(185,186)$ \\
\hline 135150 & Birt-Hogg-Dubé syndrome & FLCN & Basal body; axoneme & $(187)$ \\
\hline 201000 & Carpenter syndrome & RAB23 & Axoneme & $(200,201)$ \\
\hline 616897 & Complex lethal osteochondrodysplasia & TAPT1 & Basal body & $(189)$ \\
\hline NO MIM ID & $\begin{array}{l}\text { A novel syndrome with multiple congenital } \\
\text { malformations and developmental delay }\end{array}$ & USP9X & Axoneme & $(190)$ \\
\hline 601707 & Curry-Jones syndrome & SMO & Axoneme & $(191)$ \\
\hline 607131 & Al-Gazali-Bakalinova syndrome & KIF7 & Axoneme & $(192)$ \\
\hline 236680614120 & Hydrolethalus & $\begin{array}{l}\text { HYLS1; KIF7; } \\
\text { KIAA0586 }\end{array}$ & Basal body; axoneme; basal body & $(193-195)$ \\
\hline 175700 & Greig cephalopolysyndactyly syndrome & GLI3 & Axoneme (tip) & $(196)$ \\
\hline 612651 & $\begin{array}{l}\text { Lethal endocrine-cerebro-osteodysplasia } \\
\text { syndrome }\end{array}$ & ICK & IFT & $(197)$ \\
\hline NO MIM ID & Pituitary stalk interruption syndrome & GPR161 & Axoneme & $(198)$ \\
\hline 300707 & $\begin{array}{l}\text { Syndactyly-telecanthus-anogenital and renal } \\
\text { malformations syndrome }\end{array}$ & FAM58A & Probably cytosolic & $(202)$ \\
\hline
\end{tabular}

MIM, Mendelian Inheritance in Man; IFT, intraflagellar transport.

have been reported, such as MTS identified in OFD types 4, 6 and 14, and tibial abnormalities observed in OFD types 4, 8 and $12(177,178)$.

Other unclassified subtypes have also been described, which are characterized, in addition to the typical features, by fused kidneys (179), tetralogy of Fallot $(179,180)$, coarctation of the aorta (181), corpus callosum agenesis (179), cerebellar vermis hypoplasia, DW malformation, ID, 12th rib hypoplasia (174) and short mesoaxial phalanges (182).

\section{Conclusions}

Increasing use of whole exome sequencing has enabled the discovery of new causal genes in ciliopathies. Combined efforts have been made in the fields of proteomics, cell biology and model organisms to link the genes with their phenotypic effect. Taken together, all these studies have improved our knowledge on recognized ciliopathies, confirmed the proposed cilia-related disorders or identified new ciliary diseases.

Since Baker and Beales (183) proposed 72 conditions as candidates for ciliopathic disorders in 2009, several have been included in the group of known ciliopathies (Table II), increasing their number to 35 (184-202).

By contrast, other conditions were excluded from the list of possible or likely ciliopathies following the determination of their genetic background, including Kabuki syndrome (type 1 MIM, 147920; type 2 MIM, 300867) following identification of its causal genes, MLL2 (MIM, 602113) and KDM6A (MIM, 300128) $(203,204)$, or Neu-Laxova syndrome (type 1:
MIM, 256520; type 2: MIM, 616038) due to the discovery of its causal genes, PHGDG (MIM, 606879) and PSAT1 (MIM, 610936) (205,206).

The delineation of the ciliary proteome and its interaction with extraciliary molecules opens new perspectives in reclassifying cilia-related disorders. Thus, the disorders characterized by ciliopathy-overlapping phenotypes, the causal genes of which are not expressed in the ciliary assembly, but interfere with ciliogenesis or the cilia signaling network, have been termed ciliopathy-like disorders. A representative example is Cohen syndrome (MIM, 216550), which is defined by obesity, developmental delay, retinal degeneration and intermittent neutropenia (207), and is caused by mutations in VPS13B (MIM, 607817) (208). The expression product, which is localized to the Golgi apparatus, may impair processing of ciliary components (207). Townes-Brocks syndrome (MIM, 107480), which is characterized by hearing impairment, PKD, ESRD, imperforate anus and digit malformations (209), is caused by mutations in the SALL1 (MIM, 602218) gene, which encodes a zinc-finger transcription factor; its interaction with two ciliogenesis suppressors, CEP97 (MIM, 615864) and CCP110 (MIM, 609544), leads to cilia formation and function impairment (210). For these ciliopathy-like conditions, Reiter and Leroux (110) proposed the term second-order ciliopathies, whereas first-order ciliopathies are defined as disorders in which disease-associated proteins are expressed in the primary ciliary compartment. Although applying this classification is seemingly straightforward, unexpected evidence has uncovered the possibility of a condition being 
either first- or second-order, thus complicating the picture. One such example is MKS, a well-known ciliopathy caused by mutations in genes encoding proteins that are localized in the transition zone (101). A recent study identified a new causal gene for MKS, TXNDC15 (MIM, 617778), a non-ciliary gene, the bi-allelic mutations of which lead to abnormal cilia biogenesis (211).

Numerous conditions remain to be elucidated, either due to the fact that the genetic cause has not been uncovered or since the pathophysiological mechanism underlying the phenotype remains elusive. Predicting organ involvement and, consequently, phenotype severity based on genetic defects also represents a major challenge.

Future research will hopefully provide new insights that may help reorganize and further elucidate the striking field of ciliopathies.

\section{Acknowledgements}

The authors are grateful to Dr Costel Darie, Associate Professor of Chemistry and Biomolecular Science, Clarkson University (Potsdam, NY, USA) for reviewing this work.

\section{Funding}

No funding was received.

\section{Availability of data and materials}

Not applicable.

\section{Authors' contributions}

IOF collect the data, wrote the manuscript, prepared the figures and the tables. MBu wrote the manuscript. MBa revised and approved the manuscript. All authors read and approved the final manuscript. Data authentication is not applicable.

\section{Ethics approval and consent to participate}

Not applicable.

\section{Patient consent for publication}

Not applicable.

\section{Competing interests}

The authors declare that they have no competing interests.

\section{References}

1. Badano JL, Mitsuma N, Beales PL and Katsanis N: The ciliopathies: An emerging class of human genetic disorders. Annu Rev Genomics Hum Genet 7: 125-148, 2006.

2. Waters AM and Beales PL: Ciliopathies: An expanding disease spectrum. Pediatr Nephrol 26: 1039-1056, 2011.

3. Moore A, Escudier E, Roger G, Tamalet A, Pelosse B, Marlin S, Clément A, Geremek M, Delaisi B, Bridoux AM, et al: RPGR is mutated in patients with a complex $\mathrm{X}$ linked phenotype combining primary ciliary dyskinesia and retinitis pigmentosa. J Med Genet 43: 326-333, 2006.
4. Budny B, Chen W, Omran H, Fliegauf M, Tzschach A, Wisniewska M, Jensen LR, Raynaud M, Shoichet SA, Badura M, et al: A novel X-linked recessive mental retardation syndrome comprising macrocephaly and ciliary dysfunction is allelic to oral-facial-digital type I syndrome. Hum Genet 120: 171-178, 2006.

5. Moalem S, Keating S, Shannon P, Thompson M, Millar K, Nykamp K, Forster A, Noor A and Chitayat D: Broadening the ciliopathy spectrum: Motile cilia dyskinesia, and nephronophthisis associated with a previously unreported homozygous mutation in the INVS/NPHP2 gene. Am J Med Genet A $161 \mathrm{~A}$ : 1792-1796, 2013.

6. Shapiro AJ, Zariwala MA, Ferkol T, Davis SD, Sagel SD, Dell SD Rosenfeld M, Olivier KN, Milla C, Daniel SJ, et al: Diagnosis, monitoring, and treatment of primary ciliary dyskinesia: PCD foundation consensus recommendations based on state of the art review. Pediatr Pulmonol 51: 115-132, 2016.

7. Tobin JL and Beales PL: The nonmotile ciliopathies. Genet Med 11: 386-402, 2009

8. Leeuwenhoek AV: Observations, communicated to the publisher by $\mathrm{Mr}$. Antony van Leewenhoeck, in a dutch letter of the 9th Octob. 1676. Here English'd: Concerning little animals by him observed in rain-well-sea- and snow water; as also in water wherein pepper had lain infused. Philosophical Transactions 12: 821-831, 1677.

9. Lee L: Mechanisms of mammalian ciliary motility: Insights from primary ciliary dyskinesia genetics. Gene 473: 57-66, 2011.

10. Guo J, Higginbotham H, Li J, Nichols J, Hirt J, Ghukasyan V and Anton ES: Developmental disruptions underlying brain abnormalities in ciliopathies. Nat Commun 6: 7857, 2015.

11. Chang CF, Schock EN, Attia AC, Stottmann RW and Brugmann SA: The ciliary baton: Orchestrating neural crest cell development. Curr Top Dev Biol 111: 97-134, 2015.

12. Mirvis M, Stearns T and James Nelson W: Cilium structure, assembly, and disassembly regulated by the cytoskeleton. Biochem J 475: 2329-2353, 2018.

13. Marshall WF and Nonaka S: Cilia: Tuning in to the cell's antenna. Curr Biol 16: R604-R614, 2006.

14. Roberts AJ, Kon T, Knight PJ, Sutoh K and Burgess SA: Functions and mechanics of dynein motor proteins. Nat Rev Mol Cell Biol 14: 713-726, 2013.

15. Linck R, Fu X, Lin J, Ouch C, Schefter A, Steffen W, Warren P and Nicastro D: Insights into the structure and function of ciliary and flagellar doublet microtubules: Tektins, $\mathrm{Ca}^{2+}$-binding proteins, and stable protofilaments. J Biol Chem 289: 17427-17444, 2014.

16. Reiter JF, Blacque OE and Leroux MR: The base of the cilium: Roles for transition fibres and the transition zone in ciliary formation, maintenance and compartmentalization. EMBO Rep 13: 608-618, 2012.

17. Vertii A, Hung HF, Hehnly H and Doxsey S: Human basal body basics. Cilia 5: 13, 2016.

18. Satir P and Christensen ST: Overview of structure and function of mammalian cilia. Annu Rev Physiol 69: 377-400, 2007.

19. Hu Q, Milenkovic L, Jin H, Scott MP, Nachury MV, Spiliotis ET and Nelson WJ: A septin diffusion barrier at the base of the primary cilium maintains ciliary membrane protein distribution. Science 329: 436-439, 2010.

20. Fisch C and Dupuis-Williams P: Ultrastructure of cilia and flagella-back to the future!. Biol Cell 103: 249-270, 2011.

21. Czarnecki PG and Shah JV: The ciliary transition zone: From morphology and molecules to medicine. Trends Cell Biol 22: 201-210, 2012.

22. Nonaka S, Tanaka Y, Okada Y, Takeda S, Harada A, Kanai Y, Kido $\mathrm{M}$ and Hirokawa N: Randomization of left-right asymmetry due to loss of nodal cilia generating leftward flow of extraembryonic fluid in mice lacking KIF3B motor protein. Cell 95: 829-837, 1998.

23. Afzelius BA: Cilia-related diseases. J Pathol 204: 470-477, 2004.

24. Dabdoub A and Kelley MW: Planar cell polarity and a potential role for a Wnt morphogen gradient in stereociliary bundle orientation in the mammalian inner ear. J Neurobiol 64: 446-457, 2005.

25. Hirokawa N, Tanaka Y, Okada Y and Takeda S: Nodal flow and the generation of left-right asymmetry. Cell 125: 33-45, 2006

26. Hamada $\mathrm{H}$ : Roles of motile and immotile cilia in left-right symmetry breaking. In: Etiology and Morphogenesis of Congenital Heart Disease: From Gene Function and Cellular Interaction to Morphology. Nakanishi T, Markwald RR, Baldwin HS, Keller BB, Srivastava D and Yamagishi H (eds). Springer, Tokyo, pp57-65, 2016. 
27. Bloodgood RA: From central to rudimentary to primary: The history of an underappreciated organelle whose time has come. The primary cilium. Methods Cell Biol 94: 3-52, 2009.

28. Webber WA and Lee J: Fine structure of mammalian renal cilia. Anat Rec 182: 339-343, 1975

29. Pazour GJ, Dickert BL, Vucica Y, Seeley ES, Rosenbaum JL, Witman GB and Cole DG: Chlamydomonas IFT88 and its mouse homologue, polycystic kidney disease gene tg737, are required for assembly of cilia and flagella. J Cell Biol 151: 709-718, 2000

30. Pazour GJ, San Agustin JT, Follit JA, Rosenbaum JL and Witman GB: Polycystin-2 localizes to kidney cilia and the ciliary level is elevated in orpk mice with polycystic kidney disease. Curr Biol 12: R378-R380, 2002.

31. Gradilone SA, Masyuk AI, Splinter PL, Banales JM, Huang BQ, Tietz PS, Masyuk TV and Larusso NF: Cholangiocyte cilia express TRPV4 and detect changes in luminal tonicity inducing bicarbonate secretion. Proc Natl Acad Sci USA 104: 19138-19143, 2007.

32. Mansini AP, Peixoto E, Jin S, Richard S and Gradilone SA: The chemosensory function of primary cilia regulates cholangiocyte migration, invasion, and tumor growth. Hepatology 69 : $1582-1598,2019$

33. Masyuk AI, Gradilone SA, Banales JM, Huang BQ, Masyuk TV, Lee SO, Splinter PL, Stroope AJ and Larusso NF: Cholangiocyte primary cilia are chemosensory organelles that detect biliary nucleotides via P2Y12 purinergic receptors. Am J Physiol Gastrointest Liver Physiol 295: G725-G734, 2008

34. Praetorius HA and Spring KR: Bending the MDCK cell primary cilium increases intracellular calcium. J Membr Biol 184: 71-79, 2001.

35. Hou Y and Witman GB: Dynein and intraflagellar transport. Exp Cell Res 334: 26-34, 2015.

36. Pedersen LB and Rosenbaum JL: Intraflagellar transport (IFT) role in ciliary assembly, resorption and signalling. Curr Top Dev Biol 85: 23-61, 2008.

37. Christensen ST, Clement CA, Satir P and Pedersen LB: Primary cilia and coordination of receptor tyrosine kinase (RTK) signalling. J Pathol 226: 172-184, 2012.

38. Wheway G, Nazlamova L and Hancock JT: Signaling through the primary cilium. Front Cell Dev Biol 6: 8, 2018.

39. Veland IR, Awan A, Pedersen LB, Yoder BK and Christensen ST: Primary cilia and signaling pathways in mammalian development, health and disease. Nephron Physiol 111: p39-p53, 2009.

40. Cardenas-Rodriguez $\mathrm{M}$ and Badano JL: Ciliary biology: Understanding the cellular and genetic basis of human ciliopathies. Am J Med Genet C Semin Med Genet 151C: 263-280, 2009.

41. Logan CY and Nusse R: The Wnt signaling pathway in development and disease. Annu Rev Cell Dev Biol 20: 781-810, 2004.

42. Grigoryan T, Wend P, Klaus A and Birchmeier W: Deciphering the function of canonical Wnt signals in development and disease: Conditional loss- and gain-of-function mutations of beta-catenin in mice. Genes Dev 22: 2308-2341, 2008.

43. Reya T, Duncan AW, Ailles L, Domen J, Scherer DC, Willert K, Hintz L, Nusse R and Weissman IL: A role for Wnt signalling in self-renewal of haematopoietic stem cells. Nature 423: 409-414, 2003

44. Komiya Y and Habas R: Wnt signal transduction pathways. Organogenesis 4: 68-75, 2008.

45. Abdelhamed ZA, Wheway G, Szymanska K, Natarajan S, Toomes C, Inglehearn C and Johnson CA: Variable expressivity of ciliopathy neurological phenotypes that encompass Meckel-Gruber syndrome and Joubert syndrome is caused by complex de-regulated ciliogenesis, Shh and Wnt signalling defects. Hum Mol Genet 22: 1358-1372, 2013.

46. Wheway G, Abdelhamed Z, Natarajan S, Toomes C, Inglehearn C and Johnson CA: Aberrant Wnt signalling and cellular over-proliferation in a novel mouse model of Meckel-Gruber syndrome. Dev Biol 377: 55-66, 2013.

47. Lin F, Hiesberger T, Cordes K, Sinclair AM, Goldstein LS Somlo S and Igarashi P: Kidney-specific inactivation of the KIF3A subunit of kinesin-II inhibits renal ciliogenesis and produces polycystic kidney disease. Proc Natl Acad Sci USA 100 5286-5291, 2003

48. Anvarian Z, Mykytyn K, Mukhopadhyay S, Pedersen LB and Christensen ST: Cellular signalling by primary cilia in development, organ function and disease. Nat Rev Nephrol 15: 199-219, 2019.

49. von Maltzahn J, Chang NC, Bentzinger CF and Rudnicki MA: Wnt signaling in myogenesis. Trends Cell Biol 22: 602-609, 2012.

50. Salinas PC: Wnt signaling in the vertebrate central nervous system: From axon guidance to synaptic function. Cold Spring Harb Perspect Biol 4: a008003, 2012.

51. Eggenschwiler JT and Anderson KV: Cilia and developmental signaling. Annu Rev Cell Dev Biol 23: 345-373, 2007.
52. Varjosalo $M$ and Taipale J: Hedgehog: Functions and mechanisms. Genes Dev 22: 2454-2472, 2008.

53. Schneider L, Clement CA, Teilmann SC, Pazour GJ, Hoffmann EK, Satir P and Christensen ST: PDGFRalphaalpha signaling is regulated through the primary cilium in fibroblasts. Curr Biol 15: 1861-1866, 2005.

54. Clement DL, Mally S, Stock C, Lethan M, Satir P, Schwab A, Pedersen SF and Christensen ST: PDGFR $\alpha$ signaling in the primary cilium regulates NHE1-dependent fibroblast migration via coordinated differential activity of MEK1/2-ERK1/2-p90RSK and AKT signaling pathways. J Cell Sci 126: 953-965, 2013.

55. Pala R, Alomari N and Nauli SM: Primary cilium-dependent signaling mechanisms. Int J Mol Sci 18: 2272, 2017.

56. Heldin $\mathrm{CH}$ : Targeting the PDGF signaling pathway in the treatment of non-malignant diseases. J Neuroimmune Pharmacol 9: 69-79, 2014

57. Nishimura Y, Kasahara K, Shiromizu T, Watanabe M and Inagaki M: Primary cilia as signaling hubs in health and disease. Adv Sci (Weinh) 6: 1801138, 2018.

58. Schou KB, Pedersen LB and Christensen ST: Ins and outs of GPCR signaling in primary cilia. EMBO Rep 16: 1099-1113, 2015.

59. Hilgendorf KI, Johnson CT and Jackson PK: The primary cilium as a cellular receiver: Organizing ciliary GPCR signaling. Curr Opin Cell Biol 39: 84-92, 2016.

60. Ezratty EJ, Stokes N, Chai S, Shah AS, Williams SE and Fuchs E: A role for the primary cilium in Notch signaling and epidermal differentiation during skin development. Cell 145: 1129-1141, 2011.

61. Clement CA, Ajbro KD, Koefoed K, Vestergaard ML, Veland IR, Henriques de Jesus MP, Pedersen LB, Benmerah A, Andersen CY, Larsen LA and Christensen ST: TGF- $\beta$ signaling is associated with endocytosis at the pocket region of the primary cilium. Cell Rep 3: 1806-1814, 2013.

62. Vestergaard ML, Awan A, Warzecha CB, Christensen ST and Andersen CY: Immunofluorescence microscopy and mRNA analysis of human embryonic stem cells (hESCs) including primary cilia associated signaling pathways. Methods Mol Biol 1307: 123-140, 2016

63. Basten SG and Giles RH: Functional aspects of primary cilia in signaling, cell cycle and tumorigenesis. Cilia 2: 6, 2013.

64. Zhong M, Zhao X, Li J, Yuan W, Yan G, Tong M, Guo S, Zhu Y, Jiang Y, Liu Y and Jiang Y: Tumor suppressor folliculin regulates mTORC1 through primary Cilia. J Biol Chem 291: 11689-11697, 2016.

65. Boehlke C, Kotsis F, Patel V, Braeg S, Voelker H, Bredt S, Beyer T, Janusch H, Hamann C, Gödel M, et al: Primary cilia regulate mTORC1 activity and cell size through Lkb1. Nat Cell Biol 12: 1115-1122, 2010.

66. Leitch CC and Zaghloul NA: BBS4 is necessary for ciliary localization of TrkB receptor and activation by BDNF. PLoS One 9: e98687, 2014.

67. Lee JE and Gleeson JG: A systems-biology approach to understanding the ciliopathy disorders. Genome Med 3: 59, 2011.

68. Ansley SJ, Badano JL, Blacque OE, Hill J, Hoskins BE, Leitch CC, Kim JC, Ross AJ, Eichers ER, Teslovich TM, et al: Basal body dysfunction is a likely cause of pleiotropic Bardet-Biedl syndrome. Nature 425: 628-633, 2003.

69. Laurence JZ and Moon RC: Four cases of 'retinitis pigmentosa' occurring in the same family, and accompanied by general imperfections of development. 1866. Obes Res 3: 400-403, 1995

70. Moore SJ, Green JS, Fan Y, Bhogal AK, Dicks E, Fernandez BA, Stefanelli M, Murphy C, Cramer BC, Dean JC, et al: Clinical and genetic epidemiology of Bardet-Biedl syndrome in Newfoundland: a 22-year prospective, population-based, cohort study. Am J Med Genet A 132A: 352-360, 2005.

71. Mitchison HM and Valente EM: Motile and non-motile cilia in human pathology: From function to phenotypes. J Pathol 241: 294-309, 2017.

72. Hildebrandt F and Zhou W: Nephronophthisis-associated ciliopathies. J Am Soc Nephrol 18: 1855-1871, 2007.

73. Bergmann C: Early and severe polycystic kidney disease and related ciliopathies: An emerging field of interest. Nephron 141: 50-60, 2019.

74. Srivastava S, Molinari E, Raman S and Sayer JA: Many Genes-One disease? Genetics of nephronophthisis (NPHP) and NPHP-Associated disorders. Front Pediatr 5: 287, 2018

75. Bergmann C: Genetics of autosomal recessive polycystic kidney disease and its differential diagnoses. Front Pediatr 5: 221, 2018.

76. Salomon R, Saunier S and Niaudet P: Nephronophthisis. Pediatr Nephrol 24: 2333-2344, 2009. 
77. Srivastava S and Sayer JA: Nephronophthisis. J Pediatr Genet 3: 103-114, 2014

78. Jenkins D and Beales PL: Genes and mechanisms in human ciliopathies. In: Emery and Rimoin's Principles and Practice of Medical Genetics. Rimoin D, Pyeritz R and Korf B (eds) Academic Press, Oxford, pp1-36, 2013.

79. Gunay-Aygun M: Liver and kidney disease in ciliopathies. Am J Med Genet C Semin Med Genet 151C: 296-306, 2009.

80. Brancati F, Iannicelli M, Travaglini L, Mazzotta A, Bertini E, Boltshauser E, D'Arrigo S, Emma F, Fazzi E, Gallizzi R, et al: MKS3/TMEM67 mutations are a major cause of $\mathrm{COACH}$ Syndrome, a Joubert Syndrome related disorder with liver involvement. Hum Mutat 30: E432-E442, 2009.

81. Doherty D, Parisi MA, Finn LS, Gunay-Aygun M, Al-Mateen M, Bates D, Clericuzio C, Demir H, Dorschner M, van Essen AJ, et al: Mutations in 3 genes (MKS3, CC2D2A and RPGRIP1L) cause $\mathrm{COACH}$ syndrome (Joubert syndrome with congenital hepatic fibrosis). J Med Genet 47: 8-21, 2010.

82. Parisi MA: Clinical and molecular features of Joubert syndrome and related disorders. Am J Med Genet C Semin Med Genet 151C: 326-340, 2009.

83. Brancati F, Dallapiccola B and Valente EM: Joubert Syndrome and related disorders. Orphanet J Rare Dis 5: 20, 2010.

84. Berger W, Kloeckener-Gruissem B and Neidhardt J: The molecular basis of human retinal and vitreoretinal diseases. Prog Retin Eye Res 29: 335-375, 2010.

85. Chung DC and Traboulsi EI: Leber congenital amaurosis: Clinical correlations with genotypes, gene therapy trials update, and future directions. J AAPOS 13: 587-592, 2009.

86. Wente S, Schroder S, Buckard J, Büttel HM, von Deimling F, Diener W, Häussler M, Hübschle S, Kinder S, Kurlemann G, et al: Nosological delineation of congenital ocular motor apraxia type Cogan: An observational study. Orphanet J Rare Dis 11: 104 2016.

87. Valente EM, Dallapiccola B and Bertini E: Joubert syndrome and related disorders. Handb Clin Neurol 113: 1879-1888, 2013.

88. Poretti A, Snow J, Summers AC, Tekes A, Huisman TAGM, Aygun N, Carson KA, Doherty D, Parisi MA, Toro C, et al: Joubert syndrome: Neuroimaging findings in 110 patients in correlation with cognitive function and genetic cause. $\mathrm{J}$ Med Genet 54: 521-529, 2017.

89. Romani M, Micalizzi A and Valente EM: Joubert syndrome: Congenital cerebellar ataxia with the molar tooth. Lancet Neurol 12: 894-905, 2013.

90. Poretti A, Boltshauser E, Loenneker T, Valente EM, Brancati F, Il'yasov $\mathrm{K}$ and Huisman TA: Diffusion tensor imaging in Joubert syndrome. AJNR Am J Neuroradiol 28: 1929-1933, 2007.

91. Valente EM, Brancati F and Dallapiccola B: Genotypes and phenotypes of Joubert syndrome and related disorders. Eur J Med Genet 51: 1-23, 2008.

92. Akizu N, Silhavy JL, Rosti RO, Scott E, Fenstermaker AG, Schroth J, Zaki MS, Sanchez H, Gupta N, Kabra M, et al Mutations in CSPP1 lead to classical Joubert syndrome. Am J Hum Genet 94: 80-86, 2014.

93. Khan S, Lin S, Harlalka GV, Ullah A, Shah K, Khalid S, Mehmood S, Hassan MJ, Ahmad W, Self JE, et al: BBS5 and INPP5E mutations associated with ciliopathy disorders in families from Pakistan. Ann Hum Genet 83: 477-482, 2019.

94. Srour M, Schwartzentruber J, Hamdan FF, Ospina LH, Patry L, Labuda D, Massicotte C, Dobrzeniecka S, Capo-Chichi JM, Papillon-Cavanagh S, et al: Mutations in C5ORF42 cause Joubert syndrome in the French Canadian population. Am J Hum Genet 90: 693-700, 2012.

95. Verma PK and El-Harouni AA: Review of literature: Genes related to postaxial polydactyly. Front Pediatr 3: 8, 2015.

96. Marion V, Stutzmann F, Gerard M, De Melo C, Schaefer E, Claussmann A, Hellé S, Delague V, Souied E, Barrey C, et al: Exome sequencing identifies mutations in LZTFL1, a BBSome and smoothened trafficking regulator, in a family with Bardet--Biedl syndrome with situs inversus and insertional polydactyly. J Med Genet 49: 317-321, 2012.

97. Figuera LE, Rivas F and Cantu JM: Oral-facial-digital syndrome with fibular aplasia: A new variant. Clin Genet 44: 190-192, 1993.

98. Kannu P, McFarlane JH, Savarirayan R and Aftimos S: An unclassifiable short rib-polydactyly syndrome with acromesomelic hypomineralization and campomelia in siblings. Am J Med Genet A 143A: 2607-2611, 2007

99. Schmidts M and Mitchison HM: Severe skeletal abnormalities caused by defects in retrograde intraflagellar transport dyneins. King SM (ed). Academic Press, pp356-401, 2018.
100. Schmidts M: Clinical genetics and pathobiology of ciliary chondrodysplasias. J Pediatr Genet 3: 46-94, 2014.

101. Hartill V, Szymanska K, Sharif SM, Wheway G and Johnson CA Meckel-Gruber syndrome: An update on diagnosis, clinical management, and research advances. Front Pediatr 5: 244, 2017.

102. Doherty D, Glass IA, Siebert JR, Strouse PJ, Parisi MA, Shaw DW, Chance PF, Barr M Jr and Nyberg D: Prenatal diagnosis in pregnancies at risk for Joubert syndrome by ultrasound and MRI. Prenat Diagn 25: 442-447, 2005.

103. Sepulveda W, Sebire NJ, Souka A, Snijders RJ and Nicolaides KH: Diagnosis of the Meckel-Gruber syndrome at eleven to fourteen weeks' gestation. Am J Obstet Gynecol 176: 316-319, 1997.

104. Reece EA and Goldstein I: Early prenatal diagnosis of hydrocephalus. Am J Perinatol 14: 69-73, 1997.

105. den Hollander NS, Robben SG, Hoogeboom AJ, Niermeijer MF and Wladimiroff JW: Early prenatal sonographic diagnosis and follow-up of Jeune syndrome. Ultrasound Obstet Gynecol 18: $378-383,2001$

106. Poretti A, Brehmer U, Scheer I, Bernet V and Boltshauser E: Prenatal and neonatal MR imaging findings in oral-facial-digital syndrome type VI. AJNR Am J Neuroradiol 29: 1090-1091, 2008.

107. Beales PL and Kenny TD (eds): Towards the diagnosis of a ciliopathy. In: Ciliopathies: A Reference for Clinicians . Oxford University Press, Oxford, pp1-7, 2013.

108. Katsanis N, Beales PL, Woods MO, Lewis RA, Green JS Parfrey PS, Ansley SJ, Davidson WS and Lupski JR: Mutations in MKKS cause obesity, retinal dystrophy and renal malformations associated with Bardet-Biedl syndrome. Nat Genet 26 : 67-70, 2000.

109. Slavotinek AM, Stone EM, Mykytyn K, Heckenlively JR, Green JS, Heon E, Musarella MA, Parfrey PS, Sheffield VC and Biesecker LG: Mutations in MKKS cause Bardet-Biedl syndrome. Nat Genet 26: 15-16, 2000.

110. Reiter JF and Leroux MR: Genes and molecular pathways underpinning ciliopathies. Nat Rev Mol Cell Biol 18: 533-547, 2017.

111. Shaheen R, Szymanska K, Basu B, Patel N, Ewida N, Faqeih E, Al Hashem A, Derar N, Alsharif H, Aldahmesh MA, et al: Characterizing the morbid genome of ciliopathies. Genome Biol 17: 242, 2016.

112. Lindstrand A, Davis EE, Carvalho CM, Pehlivan D, Willer JR, Tsai IC, Ramanathan S, Zuppan C, Sabo A, Muzny D, et al: Recurrent CNVs and SNVs at the NPHP1 locus contribute pathogenic alleles to Bardet-Biedl syndrome. Am J Hum Genet 94: 745-754, 2014.

113. Lindstrand A, Frangakis S, Carvalho CM, Richardson EB, McFadden KA, Willer JR, Pehlivan D, Liu P, Pediaditakis IL, Sabo A, et al: Copy-Number variation contributes to the mutational load of Bardet-Biedl syndrome. Am J Hum Genet 99: 318-336, 2016.

114. Fauser S, Munz M and Besch D: Further support for digenic inheritance in Bardet-Biedl syndrome. J Med Genet 40: e104, 2003.

115. Katsanis N: The oligogenic properties of Bardet-Biedl syndrome. Hum Mol Genet 13 Spec No 1: R65-R71, 2004.

116. Katsanis N, Ansley SJ, Badano JL, Eichers ER, Lewis RA, Hoskins BE, Scambler PJ, Davidson WS, Beales PL and Lupski JR: Triallelic inheritance in Bardet-Biedl syndrome, a Mendelian recessive disorder. Science 293: 2256-2259, 2001.

117. Katsanis N, Eichers ER, Ansley SJ, Lewis RA, Kayserili H, Hoskins BE, Scambler PJ, Beales PL and Lupski JR: BBS4 is a minor contributor to Bardet-Biedl syndrome and may also participate in triallelic inheritance. Am J Hum Genet 71: 22-29, 2002.

118. Beales PL, Badano JL, Ross AJ, Ansley SJ, Hoskins BE Kirsten B, Mein CA, Froguel P, Scambler PJ, Lewis RA, et al: Genetic interaction of BBS1 mutations with alleles at other BBS loci can result in non-Mendelian Bardet-Biedl syndrome. Am J Hum Genet 72: 1187-1199, 2003

119. Abu-Safieh L, Al-Anazi S, Al-Abdi L, Hashem M, Alkuraya $\mathrm{H}$ Alamr M, Sirelkhatim MO, Al-Hassnan Z, Alkuraya B, Mohamed JY, et al: In search of triallelism in Bardet-Biedl syndrome. Eur J Hum Genet 20: 420-427, 2012.

120. Delvallée C, Nicaise S, Antin M, Leuvrey AS, Nourisson E, Leitch CC, Kellaris G, Stoetzel C, Geoffroy V, Scheidecker S, et al: A BBS1 SVA F retrotransposon insertion is a frequent cause of Bardet-Biedl syndrome. Clin Genet 99: 318-324, 2021.

121. Davis EE and Katsanis N: The ciliopathies: A transitional model into systems biology of human genetic disease. Curr Opin Genet Dev 22: 290-303, 2012 
122. Badano JL, Kim JC, Hoskins BE, Lewis RA, Ansley SJ, Cutler DJ, Castellan C, Beales PL, Leroux MR and Katsanis N Heterozygous mutations in BBS1, BBS2 and BBS6 have a potential epistatic effect on Bardet-Biedl patients with two mutations at a second BBS locus. Hum Mol Genet 12: 1651-1659, 2003.

123. Badano JL, Leitch CC, Ansley SJ, May-Simera H, Lawson S, Lewis RA, Beales PL, Dietz HC, Fisher S and Katsanis N Dissection of epistasis in oligogenic Bardet-Biedl syndrome. Nature 439: 326-330, 2006.

124. Slavotinek A and Biesecker LG: Genetic modifiers in human development and malformation syndromes, including chaperone proteins. Hum Mol Genet 12 Spec No 1: R45-R50, 2003.

125. Hildebrandt F, Benzing T and Katsanis N: Ciliopathies. N Engl J Med 364: 1533-1543, 2011

126. Novarino G, Akizu N and Gleeson JG: Modeling human disease in humans: The ciliopathies. Cell 147: 70-79, 2011.

127. Zaki MS, Sattar S, Massoudi RA and Gleeson JG: Co-occurrence of distinct ciliopathy diseases in single families suggests genetic modifiers. Am J Med Genet A 155A: 3042-3049, 2011

128. Khanna H, Davis EE, Murga-Zamalloa CA, Estrada-Cuzcano A, Lopez I, den Hollander AI, Zonneveld MN, Othman MI, Waseem N, Chakarova CF, et al: A common allele in RPGRIP1L is a modifier of retinal degeneration in ciliopathies. Nat Genet 41 : 739-745, 2009

129. Bujakowska KM, Liu Q and Pierce EA: Photoreceptor cilia and retinal ciliopathies. Cold Spring Harb Perspect Biol 9: a028274, 2017.

130. Goldberg AF, Moritz OL and Williams DS: Molecular basis for photoreceptor outer segment architecture. Prog Retin Eye Res 55: 52-81, 2016.

131. Estrada-Cuzcano A, Roepman R, Cremers FP, den Hollander AI and Mans DA: Non-syndromic retinal ciliopathies: Translating gene discovery into therapy. Hum Mol Genet 21: R111-R124, 2012

132. den Hollander AI, Roepman R, Koenekoop RK and Cremers FP: Leber congenital amaurosis: Genes, proteins and disease mechanisms. Prog Retin Eye Res 27: 391-419, 2008.

133. Adams NA, Awadein A and Toma HS: The retinal ciliopathies. Ophthalmic Genet 28: 113-125, 2007

134. Marshall JD, Muller J, Collin GB, Milan G, Kingsmore SF, Dinwiddie D, Farrow EG, Miller NA, Favaretto F, Maffei P, et al: Alstrom syndrome: Mutation spectrum of ALMS1. Hum Mutat 36: 660-668, 2015.

135. Ronquillo CC, Bernstein PS and Baehr W: Senior-Loken syndrome: A syndromic form of retinal dystrophy associated with nephronophthisis. Vision Res 75: 88-97, 2012.

136. Braun DA and Hildebrandt F: Ciliopathies. Cold Spring Harb Perspect Biol 9: a028191,2017.

137. Saigusa T and Bell PD: Molecular pathways and therapies in autosomal-dominant polycystic kidney disease. Physiology (Bethesda) 30: 195-207, 2015.

138. Bergmann C: ARPKD and early manifestations of ADPKD The original polycystic kidney disease and phenocopies. Pediatr Nephrol 30: 15-30, 2015

139. Chebib FT and Torres VE: Autosomal dominant polycystic kidney disease: Core Curriculum 2016. Am J Kidney Dis 67 792-810, 2016

140. Wolf MT and Hildebrandt F: Nephronophthisis. Pediatr Nephrol 26: 181-194, 2011

141. Konig J, Kranz B, Konig S, Schlingmann KP, Titieni A, Tönshoff B, Habbig S, Pape L, Häffner K, Hansen M, et al: Phenotypic spectrum of children with nephronophthisis and related ciliopathies. Clin J Am Soc Nephrol 12: 1974-1983, 2017.

142. Zaghloul NA and Katsanis N: Mechanistic insights into Bardet-Biedl syndrome, a model ciliopathy. J Clin Invest 119 428-437, 2009.

143. Forsythe E and Beales PL: Bardet-Biedl syndrome. Eur J Hum Genet 21: 8-13, 2013

144. Forsythe R and Gunay-Aygun M: Bardet-Biedl syndrome overview. Adam MP, Ardinger HH, Pagon RA, et al (eds) GeneReviews ${ }^{\circledR}$ [Internet]. University of Washington, Seattle, WA, 2003 (updated July 23, 2020).

145. Bujakowska KM, Zhang Q, Siemiatkowska AM, Liu Q, Place E, Falk MJ, Consugar M, Lancelot ME, Antonio A, Lonjou C, et al: Mutations in IFT172 cause isolated retinal degeneration and Bardet-Biedl syndrome. Hum Mol Genet 24: 230-242, 2015.

146. Alazami AM, Alshammari MJ, Salih MA, Alzahrani F, Hijazi H, Seidahmed MZ, Abu Safieh L, Aldosary M, Khan AO and Alkuraya FS: Molecular characterization of Joubert syndrome in Saudi Arabia. Hum Mutat 33: 1423-1428, 2012.
147. StephenJ,VilbouxT,MianL,KuptanonC,SinclairCM,YildirimliD, Maynard DM, Bryant J, Fischer R, Vemulapalli M, et al: Mutations in KIAA0753 cause Joubert syndrome associated with growth hormone deficiency. Hum Genet 136: 399-408, 2017.

148. Shaheen R, Jiang N, Alzahrani F, Ewida N, Al-Sheddi T, Alobeid E, Musaev D, Stanley V, Hashem M, Ibrahim N, et al: Bi-allelic Mutations in FAM149B1 cause abnormal primary cilium and a range of ciliopathy phenotypes in humans. Am J Hum Genet 104: 731-737, 2019.

149. Radha Rama Devi A, Naushad SM and Lingappa L: Clinical and molecular diagnosis of joubert syndrome and related disorders. Pediatr Neurol 106: 43-49, 2020.

150. Oka M, Shimojima K, Yamamoto T, Hanaoka Y, Sato S, Yasuhara T, Yoshinaga H and Kobayashi K: A novel HYLS1 homozygous mutation in living siblings with Joubert syndrome. Clin Genet 89: 739-743, 2016.

151. Beck BB, Phillips JB, Bartram MP, Wegner J, Thoenes M, Pannes A, Sampson J, Heller R, Göbel H, Koerber F, et al: Mutation of POC1B in a severe syndromic retinal ciliopathy. Hum Mutat 35: 1153-1162, 2014

152. Bachmann-Gagescu R, Dempsey JC, Phelps IG, O'Roak BJ, Knutzen DM, Rue TC, Ishak GE, Isabella CR, Gorden N, Adkins J, et al: Joubert syndrome: A model for untangling recessive disorders with extreme genetic heterogeneity. J Med Genet 52: 514-522, 2015.

153. Schmidts M: Jeune syndrome and the ciliary chondrodysplasias In: Ciliopathies. Oxford University Press, Oxford, pp30-63, 2013

154. Haycraft CJ, Zhang Q, Song B, Jackson WS, Detloff PJ, Serra R and Yoder BK: Intraflagellar transport is essential for endochondral bone formation. Development 134: 307-316, 2007.

155. St-Jacques B, Hammerschmidt M and McMahon AP: Indian hedgehog signaling regulates proliferation and differentiation of chondrocytes and is essential for bone formation. Genes Dev 13: 2072-2086, 1999.

156. Schmidts M, Hou Y, Cortes CR, Mans DA, Huber C, Boldt K, Patel M, van Reeuwijk J, Plaza JM, van Beersum SE, et al: TCTEX1D2 mutations underlie Jeune asphyxiating thoracic dystrophy with impaired retrograde intraflagellar transport. Nat Commun 6: 7074, 2015

157. Zhang W, Taylor SP, Ennis HA, Forlenza KN, Duran I, Li B, Sanchez JAO, Nevarez L, Nickerson DA and Bamshad M: Expanding the genetic architecture and phenotypic spectrum in the skeletal ciliopathies. Hum Mutat 39: 152-166, 2018.

158. Ellis RW and van Creveld S: A syndrome characterized by ectodermal dysplasia, polydactyly, Chondro-Dysplasia and congenital Morbus Cordis: Report of three cases. Arch Dis Child 15: 65-84, 1940.

159. McKusick VA, Eldridge R, Hostetler JA and Egeland JA: Dwarfism in the Amish. Trans Assoc Am Physicians 77: $151-168,1964$.

160. Ruiz-Perez VL and Goodship JA: Ellis-van Creveld syndrome and Weyers acrodental dysostosis are caused by cilia-mediated diminished response to hedgehog ligands. Am J Med Genet C Semin Med Genet 151C: 341-351, 2009.

161. Howard TD, Guttmacher AE, McKinnon W, Sharma M, McKusick VA and Jabs EW: Autosomal dominant postaxial polydactyly, nail dystrophy, and dental abnormalities map to chromosome $4 \mathrm{p} 16$, in the region containing the Ellis-van Creveld syndrome locus. Am J Hum Genet 61: 1405-1412, 1997.

162. Levin LS, Perrin JC, Ose L, Dorst JP, Miller JD and McKusick VA A heritable syndrome of craniosynostosis, short thin hair, dental abnormalities, and short limbs: Cranioectodermal dysplasia. J Pediatr 90: 55-61, 1977.

163. Lin AE, Traum AZ, Sahai I, Keppler-Noreuil K, Kukolich MK, Adam MP, Westra SJ and Arts HH: Sensenbrenner syndrome (Cranioectodermal dysplasia): Clinical and molecular analyses of 39 patients including two new patients. Am J Med Genet A 161A: 2762-2776, 2013.

164. Arts HH, Bongers EM, Mans DA, van Beersum SE, Oud MM, Bolat E, Spruijt L, Cornelissen EA, Schuurs-Hoeijmakers JH, de Leeuw N, et al: C14ORF179 encoding IFT43 is mutated in Sensenbrenner syndrome. J Med Genet 48: 390-395, 2011.

165. Huber C and Cormier-Daire V: Ciliary disorder of the skeleton. Am J Med Genet C Semin Med Genet 160C: 165-174, 2012.

166. Mainzer F, Saldino RM, Ozonoff MB and Minagi H: Familial nephropathy associatdd with retinitis pigmentosa, cerebellar ataxia and skeletal abnormalities. Am J Med 49: 556-562, 1970.

167. Perrault I, Saunier S, Hanein S, Filhol E, Bizet AA, Collins F, Salih MA, Gerber S, Delphin N, Bigot K, et al: Mainzer-Saldino syndrome is a ciliopathy caused by IFT140 mutations. Am J Hum Genet 90: 864-870, 2012 
168. Beales PL, Bland E, Tobin JL, Bacchelli C, Tuysuz B, Hill J, Rix S, Pearson CG, Kai M, Hartley J, et al: IFT80, which encodes a conserved intraflagellar transport protein, is mutated in Jeune asphyxiating thoracic dystrophy. Nat Genet 39: 727-729, 2007.

169. Tuysuz B, Baris S, Aksoy F, Madazli R, Ungur S and Sever L: Clinical variability of asphyxiating thoracic dystrophy (Jeune) syndrome: Evaluation and classification of 13 patients. Am J Med Genet A 149A: 1727-1733, 2009.

170. Zhang W, Taylor SP, Nevarez L, Lachman RS, Nickerson DA and Bamshad M: IFT52 mutations destabilize anterograde complex assembly, disrupt ciliogenesis and result in short rib polydactyly syndrome. Hum Mol Genet 25: 4012-4020, 2016.

171. Duran I, Taylor SP, Zhang W, Martin J, Qureshi F, Jacques SM, Wallerstein R, Lachman RS, Nickerson DA, Bamshad M, et al: Mutations in IFT-A satellite core component genes IFT43 and IFT121 produce short rib polydactyly syndrome with distinctive campomelia. Cilia 6: 7, 2017.

172. Roosing S, Romani M,Isrie M, Rosti RO, Micalizzi A, Musaev D, Mazza T, Al-Gazali L, Altunoglu U, Boltshauser E, et al: Mutations in CEP120 cause Joubert syndrome as well as complex ciliopathy phenotypes. J Med Genet 53: 608-615, 2016

173. Bruel AL, Franco B, Duffourd Y, Thevenon J, Jego L, Lopez E, Deleuze JF, Doummar D, Giles RH, Johnson CA, et al: Fifteen years of research on oral-facial-digital syndromes: From 1 to 16 causal genes. J Med Genet 54: 371-380, 2017.

174. Li C, Jensen VL, Park K, Kennedy J, Garcia-Gonzalo FR, Romani M, De Mori R, Bruel AL, Gaillard D, Doray B, et al: MKS5 and CEP290 dependent assembly pathway of the ciliary transition zone. PLoS Biol 14: e1002416, 2016.

175. Al-Qattan MM, Shaheen R and Alkuraya FS: Expanding the allelic disorders linked to TCTN1 to include Varadi syndrome (Orofaciodigital syndrome type VI). Am J Med Genet A 173 2439-2441, 2017.

176. Franco B and Thauvin-Robinet C: Update on oral-facial-digital syndromes (OFDS). Cilia 5: 12, 2016

177. Toriello HV: Are the oral-facial-digital syndromes ciliopathies? Am J Med Genet A 149A: 1089-1095, 2009.

178. Toriello HV, Franco B, Bruel AL and Thauvin-Robinet C: Oral-Facial-Digital Syndrome Type I. In: GeneReviews((R)) Adam MP, Ardinger HH and Pagon RA (eds). University of Washington, Seattle, WA, 1993.

179. Shamseldin HE, Rajab A, Alhashem A, Shaheen R, Al-Shidi T, Alamro R, Al Harassi S and Alkuraya FS: Mutations in DDX59 implicate RNA helicase in the pathogenesis of orofaciodigital syndrome. Am J Hum Genet 93: 555-560, 2013

180. Toriyama M, Lee C, Taylor SP, Duran I, Cohn DH, Bruel AL, Tabler JM, Drew K, Kelly MR, Kim S, et al: The ciliopathy-associated CPLANE proteins direct basal body recruitment of intraflagellar transport machinery. Nat Genet 48: 648-656, 2016

181. Saari J, Lovell MA, Yu HC and Bellus GA: Compound heterozygosity for a frame shift mutation and a likely pathogenic sequence variant in the planar cell polarity-ciliogenesis gene WDPCP in a girl with polysyndactyly, coarctation of the aorta, and tongue hamartomas. Am J Med Genet A 167A: 421-427, 2015.

182. Thevenon J, Duplomb L, Phadke S, Eguether T, Saunier A, Avila M, Carmignac V, Bruel AL, St-Onge J, Duffourd Y, et al: Autosomal recessive IFT57 hypomorphic mutation cause ciliary transport defect in unclassified oral-facial-digital syndrome with short stature and brachymesophalangia. Clin Genet 90 509-517, 2016

183. Baker K and Beales PL: Making sense of cilia in disease: The human ciliopathies. Am J Med Genet C Semin Med Genet 151C: 281-295, 2009

184. Laquerriere A, Maluenda J, Camus A, Fontenas L, Dieterich K, Nolent F, Zhou J, Monnier N, Latour P, Gentil D, et al: Mutations in CNTNAP1 and ADCY6 are responsible for severe arthrogryposis multiplex congenita with axoglial defects. Hum Mo Genet 23: 2279-2289, 2014.

185. Filges I, Bruder E, Brandal K, Meier S, Undlien DE, Waage TR, Hoesli I, Schubach M, de Beer T, Sheng Y, et al: Stromme syndrome is a ciliary disorder caused by mutations in CENPF. Hum Mutat 37: 359-363, 2016

186. Waters AM, Asfahani R, Carroll P, Bicknell L,Lescai F, Bright A, Chanudet E, Brooks A, Christou-Savina S, Osman G, et al: The kinetochore protein, CENPF, is mutated in human ciliopathy and microcephaly phenotypes. J Med Genet 52: 147-156, 2015.

187. Luijten MN, Basten SG, Claessens T, Vernooij M, Scott CL, Janssen R, Easton JA, Kamps MA, Vreeburg M, Broers JL, et al: Birt-Hogg-Dube syndrome is a novel ciliopathy. Hum Mol Genet 22: 4383-4397, 2013.
188. Jenkins D, Seelow D, Jehee FS, Perlyn CA, Alonso LG, Bueno DF Donnai D, Josifova D, Mathijssen IM, Morton JE, et al: RAB23 mutations in Carpenter syndrome imply an unexpected role for hedgehog signaling in cranial-suture development and obesity. Am J Hum Genet 80: 1162-1170, 2007.

189. Symoens S, Barnes AM, Gistelinck C, Malfait F, Guillemyn B, Steyaert W, Syx D, D'hondt S, Biervliet M, De Backer J, et al: Genetic defects in TAPT1 disrupt ciliogenesis and cause a complex lethal osteochondrodysplasia. Am J Hum Genet 97: 521-534, 2015.

190. Reijnders MR, Zachariadis V, Latour B, Jolly L, Mancini GM, Pfundt R, Wu KM, van Ravenswaaij-ArtsCM, Veenstra-Knol HE, Anderlid BM, et al: De Novo Loss-of-Function mutations in USP9X cause a Female-Specific recognizable syndrome with developmental delay and congenital malformations. Am J Hum Genet 98: 373-381, 2016

191. Twigg SRF, Hufnagel RB, Miller KA, Zhou Y, McGowan SJ, Taylor J, Craft J, Taylor JC, Santoro SL, Huang T, et al: A recurrent Mosaic Mutation in SMO, encoding the Hedgehog signal transducer smoothened, is the major cause of Curry-Jones syndrome. Am J Hum Genet 98: 1256-1265, 2016.

192. Ali BR, Silhavy JL, Akawi NA, Gleeson JG and Al-Gazali L: A mutation in KIF7 is responsible for the autosomal recessive syndrome of macrocephaly, multiple epiphyseal dysplasia and distinctive facial appearance. Orphanet J Rare Dis 7: 27, 2012.

193. Putoux A, Thomas S, Coene KL, Davis EE, Alanay Y, Ogur G, Uz E, Buzas D, Gomes C, Patrier S, et al: KIF7 mutations cause fetal hydrolethalus and acrocallosal syndromes. Nat Genet 43 601-606, 2011.

194. Dammermann A, Pemble H, Mitchell BJ, McLeod I, Yates JR III, Kintner C, Desai AB and Oegema K: The hydrolethalus syndrome protein HYLS-1 links core centriole structure to cilia formation. Genes Dev 23: 2046-2059, 2009.

195. Alby C, Piquand K, Huber C, Megarbané A, Ichkou A, Legendre M, Pelluard F, Encha-Ravazi F, Abi-Tayeh G, Bessières B, et al: Mutations in KIAA0586 cause lethal ciliopathies ranging from a hydrolethalus phenotype to Short-Rib Polydactyly syndrome. Am J Hum Genet 97: 311-318, 2015.

196. Demurger F, Ichkou A, Mougou-Zerelli S, Le Merrer M, Goudefroye G, Delezoide AL, Quélin C, Manouvrier S, Baujat G, Fradin M, et al: New insights into genotype-phenotype correlation for GLI3 mutations. Eur J Hum Genet 23: 92-102, 2015.

197. Oud MM, Bonnard C, Mans DA, Altunoglu U, Tohari S, $\mathrm{Ng}$ AYJ, Eskin A, Lee H, Rupar CA, de Wagenaar NP, et al: A novel ICK mutation causes ciliary disruption and lethal endocrine-cerebro-osteodysplasia syndrome. Cilia 5: 8, 2016.

198. Karaca E, Buyukkaya R, Pehlivan D, Charng WL, Yaykasli KO, Bayram Y, Gambin T, Withers M, Atik MM, Arslanoglu I, et al: Whole-exome sequencing identifies homozygous GPR161 mutation in a family with pituitary stalk interruption syndrome. J Clin Endocrinol Metab 100: E140-147, 2015.

199. Guen VJ, Gamble C, Perez DE, Bourassa S, Zappel H, Gärtner J, Lees JA and Colas P: STAR syndrome-associated CDK10/Cyclin $M$ regulates actin network architecture and ciliogenesis. Cell Cycle 15: 678-688, 2016.

200. Alessandri JL, Dagoneau N, Laville JM, Baruteau J, Hébert JC and Cormier-Daire V: RAB23 mutation in a large family from Comoros Islands with Carpenter syndrome. Am J Med Genet A 152A: 982-986, 2010

201. Jenkins D, Baynam G, De Catte L, Elcioglu N, Gabbett MT, Hudgins L, Hurst JA, Jehee FS, Oley C and Wilkie AO Carpenter syndrome: Extended RAB23 mutation spectrum and analysis of nonsense-mediated mRNA decay. Hum Mutat 32: E2069-E2078, 2011.

202.Lefroy H, Hurst JA and Shears DJ: STAR syndrome: A further case and the first report of maternal mosaicism. Clin Dysmorphol 26: 157-160, 2017.

203. Ng SB, Bigham AW, Buckingham KJ, Hannibal MC, McMillin MJ, Gildersleeve HI, Beck AE, Tabor HK, Cooper GM, Mefford HC, et al: Exome sequencing identifies MLL2 mutations as a cause of Kabuki syndrome. Nat Genet 42: 790-793, 2010.

204. Miyake N, Koshimizu E, Okamoto N, Mizuno S, Ogata T, Nagai T, Kosho T, Ohashi H, Kato M, Sasaki G, et al: MLL2 and KDM6A mutations in patients with Kabuki syndrome. Am J Med Genet A 161A: 2234-2243, 2013

205. Shaheen R, Rahbeeni Z, Alhashem A, Faqeih E, Zhao Q, Xiong Y, Almoisheer A, Al-Qattan SM, Almadani HA, Al-Onazi N, et al: Neu-Laxova syndrome, an inborn error of serine metabolism, is caused by mutations in PHGDH. Am J Hum Genet 94: 898-904, 2014. 
206. Acuna-Hidalgo R, Schanze D, Kariminejad A, Nordgren A, Kariminejad MH, Conner P, Grigelioniene G, Nilsson D, Nordenskjöld M, Wedell A, et al: Neu-Laxova syndrome is a heterogeneous metabolic disorder caused by defects in enzymes of the L-serine biosynthesis pathway. Am J Hum Genet 95: 285-293, 2014.

207. Duplomb L, Duvet S, Picot D, Jego G, El Chehadeh-Djebbar S, Marle N, Gigot N, Aral B, Carmignac V, Thevenon J, et al: Cohen syndrome is associated with major glycosylation defects. Hum Mol Genet 23: 2391-2399, 2014

208. El Chehadeh S, Aral B, Gigot N, Thauvin-Robinet C, Donzel A Delrue MA, Lacombe D, David A, Burglen L, Philip N, et al: Search for the best indicators for the presence of a VPS13B gene mutation and confirmation of diagnostic criteria in a series of 34 patients genotyped for suspected Cohen syndrome. J Med Genet 47: 549-553, 2010.
209. Emery NJ, Seed AM, von Bayern AM and Clayton NS: Cognitive adaptations of social bonding in birds. Philos Trans R Soc Lond B Biol Sci 362: 489-505, 2007.

210. Bozal-Basterra L, Martin-Ruiz I, Pirone L, Liang Y, Sigurðsson JO, Gonzalez-Santamarta M, Giordano I, Gabicagogeascoa E, de Luca A, Rodríguez JA, et al: Truncated SALL1 impedes primary cilia function in townes-brocks syndrome. Am J Hum Genet 102: 249-265, 2018.

211. Devlin LA and Sayer JA: Renal ciliopathies. Curr Opin Genet Dev 56: 49-60, 2019.

(i) (9) This work is licensed under a Creative Commons

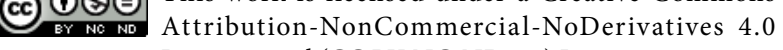
International (CC BY-NC-ND 4.0) License. 